\title{
Electromagnetic Fields and Calcium Signaling by the Voltage Dependent Anion Channel
}

\author{
Volker Ullrich, Hans-Jürgen Apell \\ Department of Biology, University of Konstanz, Konstanz, Germany \\ Email:h-j.apell@uni-konstanz.de
}

How to cite this paper: Ullrich, V. and Apell, H.-J. (2021) Electromagnetic Fields and Calcium Signaling by the Voltage Dependent Anion Channel. Open Journal of Veterinary Medicine, 11, 57-86. https://doi.org/10.4236/ojvm.2021.111004

Received: December 12, 2020

Accepted: January 26, 2021

Published: January 29, 2021

Copyright $\odot 2021$ by author(s) and Scientific Research Publishing Inc. This work is licensed under the Creative Commons Attribution International License (CC BY 4.0).

http://creativecommons.org/licenses/by/4.0/

(c) (i) Open Access

\begin{abstract}
Electromagnetic fields (EMFs) can interact with biological tissues exerting positive as well as negative effects on cell viability, but the underlying sensing and signaling mechanisms are largely unknown. So far in excitable cells EMF exposure was postulated to cause $\mathrm{Ca}^{2+}$ influx through voltage-dependent $\mathrm{Ca}$ channels (VDCC) leading to cell activation and an antioxidant response. Upon further activation oxidative stress causing DNA damage or cell death may follow. Here we report collected evidence from literature that voltage dependent anion channels (VDAC) located not only in the outer microsomal membrane but also in the cytoplasmic membrane convert to $\mathrm{Ca}^{2+}$ conducting channels of varying capacities upon subtle changes of the applied EMF even in non-excitable cells like erythrocytes. Thus, VDAC can be targeted by external EMF in both types of membranes to release $\mathrm{Ca}^{2+}$ into the cytosol. The role of frequency, pulse modulation or polarization remains to be investigated in suitable cellular models. VDACs are associated with several other proteins, among which the $18 \mathrm{kDa}$ translocator (TSPO) is of specific interest since it was characterized as the central benzodiazepine receptor in neurons. Exhibiting structural similarities with magnetoreceptors we propose that TSPO could sense the magnetic component of the EMF and thus together with VDAC could trigger physiological as well as pathological cellular responses. Pulsed EMFs in the frequency range of the brain-wave communication network may explain psychic disturbances of electromagnetic hypersensitive persons. An important support is provided from human psychology that states deficits like insomnia, anxiety or depression can be treated with diazepines that indicates apparent connections between the TSPO/VDAC complex and organismic responses to EMF.
\end{abstract}

\section{Keywords}

Ca Signaling, VDAC, Benzodiazepine Receptor, Mechanistic Concept, Pulsed EMFs, Electromagnetic Hypersensitivity, TSPO, Erythrocytes, 
NADH-Oxidase, Apoptosis, Magnetosensor, Membrane Potential, Oxidative Stress, Brain Signaling, Autism

\section{Introduction}

The digital revolution changes life in our modern world dramatically and enables mankind to solve increasingly complex problems in shorter times. Mankind is forced to act more and more in networks and relies on mobile communication that significantly affects our way of life. The technical progress is reflected in ever more rapid developments of wireless communication systems emitting EMFs from radio frequencies to microwave radiation (e.g. 3G, 4G, Wi-Fi, Bluetooth) and now 5G. This new ultra-rapid and high capacity network is currently being installed worldwide, not without increasing warnings on possible health risks for humans and living organisms in general [1] [2] [3] [4]. There are numerous reports on so-called "electromagnetic hypersensitive" persons who suffer from headache, insomnia, unrest, deficits in memory and learning, skin sensations or even depression in possible connection with mobile communication [5] [6]. Meanwhile about $8 \%$ of the human population suffer from such obviously brain-related diseases and together with the rising incidences of the burn-out syndrome [7]. In the male population a severe reduction of sperm counts [8] and breast cancer was found to increase in young women carrying their cell phone close to the breast [9]. Such epidemiological studies on humans are always subject to criticism and hence health effects by cell phone exposure were mostly disputed in literature. On this background and in view of the multiple physiological and psychological effects, it became obvious that a broad range of toxicological and mechanistic studies were required to find solid support for potential risks of microwave exposure from mobile phones and their base stations. Animal studies were the first choice in risk assessment and long-term exposure at low dosage was required to eliminate potential thermic effects of the irradiation. In a study carried out over 20 years and published in 2018 the FDA within the US National Toxicology Program performed a risk assessment with over 20,000 rats and mice showing a significant increase in glioma and its precursors in male rats (emfdata.org). In parallel a similar study by the Ramazzini Institute performed with 2448 Sprague-Dawley rats the animals developed significantly more heart Schwannomas in male rats [10]. In such animal studies [11] [12] DNA damage as well as oxidative stress symptoms were also present which suggests a causal relationship with tumor formation. Not only tumors but also developmental hazards seem to be a consequence of low-dose microwave exposure as seen in livers from fertilized chick embryos [13]. Increased mortality and severe malformations were reported in developing chicken eggs daily exposed for $50 \mathrm{~min}$ to mobile phone irradiation [14]. These authors also refer to 8 other studies with similar outcome indicating the developing chicken egg to be a reliable model for 
potential teratogenic effects of microwave irradiation. In this context results of M. Hässig et al. [15] must be mentioned which suggested nuclear cataracts in calves born upon exposure to radiation from antenna base stations during gravidity. In spite of such abundant epidemiological and toxicological data, the officially tolerable exposure levels to EMFs, designated the specific absorption rate (SAR), refers only to the thermal effects of microwave irradiation and allow heating of the skin by $1^{\circ} \mathrm{C}$, and a safety factor which still allows exposure levels of EMFs that exceed by far the level at which biological effects were reported in a vast amount of literature. The need for reliable biological tests is obvious and hence a rational and mechanistic approach is necessary to determine justifiable EMF-exposure levels. It is the goal of this review to compile the abundant data available in this field for new prospects on biochemical events triggered by exposure of tissues and cells to electromagnetic fields.

There may be a general agreement on clearly non-thermal effects of EMFs in biological systems. The amount of energy absorbed in biological tissue provided by EMFs relies crucially on frequency, intensity and exposure time. Radiation in the $\mathrm{GHz}$ range will interact preferably with electrons and primarily produce thermal effects. Pulse protocols modulated onto the carrier frequency provide, however, in their frequency spectrum components which are able to induce responses in proteins. Such signals and pulse trains with pattern in the range of milliseconds or longer are able to trigger conformational rearrangements leading to channel opening or closing. Another important question is the penetration of tissue. From basic physical principles it is known that electromagnetic radiation declines exponentially in matter due to absorption. The penetration depth, which typically is specified by the length at which the intensity at the surface is reduced to $37 \%(=1 / \mathrm{e})$, depends on the applied wavelength and the material through which the radiation has to pass. In the $\mathrm{GHz}$ range it was found, the higher the frequency the higher the absorption coefficient. Besides thermal absorption it is, however, largely unknown by which mechanisms EMFs interact with different tissues and cells and above which radiation intensities significant effects on cellular processes are probable. To understand the molecular and mechanistic pathways of cause and effect, insight into the involved cellular components has to be gained and it has to be uncovered how energy from EMFs is transferred to cellular targets. In addition, so far no published research is available that quantifies EMF effects with respect to the probability of noxious effects in dependence of radiation intensity and duration. In biophysical terms we have to determine the acceptors (and their sensitivities) that trigger biochemical and functional responses in cells. The identification of the associated biochemical components and their reactions will allow not only a prediction of the impact caused by exposure to EMFs but also a proposal of suitable test systems to study the consequences in different cells, tissues and species. Defined effects can be quantified by in vitro assays for different frequencies, modulation and pulse techniques. Such an approach will help the society to guide the current, partly 
emotional discussion on the risks of mobile-phone communication back to scientific reliability.

A broad variety of scientific reports substantiate that EMFs have been applied since decades in medicine to treat pain and enforce healing of bone fractures using EMFs with frequencies between 10 and $30 \mathrm{~Hz}$ [16] [17] [18] [19]. Growth of tumor cells could be arrested by application of alternating electric fields [20], at which $\mathrm{Ca}^{2+}$ influx through Cav1.2 channels seems to be involved. Early studies by Blackman [21] suggested $\mathrm{Ca}^{2+}$ to be involved in EMFs action on brain tissue. Furthermore, detailed studies are available that stimulation of white fast muscle fibers with $10 \mathrm{~Hz}$ caused a conversion into red slow muscle fibers due to an enforced rate of mitochondrial biogenesis [22]. Stimulation for time periods longer than certain thresholds caused significant oxidative stress in the cells which was detected and emphasized by nitration of tyrosine residues in various cytoplasmic proteins [23]. It is well established that nitrated proteins are a fingerprint of peroxynitrite $\left(\mathrm{ONOO}^{-}\right)$formation resulting from nitric oxide (NO$)$synthesis and superoxide radical $\left(\mathrm{O}_{2}^{-}\right)$generation [24]. On the other hand, peroxynitrite enhances also significantly $\mathrm{Ca}^{2+}$ levels in cells by inhibition of the Ca-ATPase as was measured also in such "overstimulated" muscle fibers [25]. Increased $\mathrm{Ca}^{2+}$ levels and oxidative stress are known to be indicators of severe cell damage and lead to cellular dysfunction and even apoptosis [26]. Overall, positive as well as negative effects of EMFs were reported, most of them being of non-thermal nature.

Our present scrutiny of the available literature on appropriate cellular metabolic processes and malfunctions can provide new insights into EMFs-related processes and will allow an advanced mechanistic approach to understand the interaction of EMFs and biological systems. Our study indicated unexpectedly the involvement of a plasma membrane voltage dependent anion channel (VDAC) in electrically non-excitable cells as a common target of EMF actions, and VDAC associated sensors as mediators. This establishes new aspects in the field of research on those cells and even on the biophysical and biochemical network that controls brain functions.

\section{Results and Discussion}

\subsection{Current Concepts of EMFs Action on Cells}

An abundance of papers on the effects of EMFs on biological systems can be found in the literature, and hundreds of them refer to biochemical findings with cells. Martin L. Pall [27], proposed a specific characteristic of the effect of EMFs in excitable cells, namely an increase of the cytoplasmic $\mathrm{Ca}^{2+}$ concentration through voltage-dependent $\mathrm{Ca}$ channels (VDCC). $\mathrm{Ca}^{2+}$ is a second messenger in cells and it is well known that the concentration of free $\mathrm{Ca}^{2+}$ is tightly regulated under physiological conditions, to maintain the cellular metabolism intact. Surplus $\mathrm{Ca}^{2+}$ is immediately stored away in intracellular repositories or pumped at a limited rate actively out of the cell. If the storage capacity or cellular energy is 
exhausted, the cytoplasmic $\mathrm{Ca}^{2+}$ concentration will be continuously enhanced. Pathological effects of such a $\mathrm{Ca}^{2+}$ overload have been investigated since many decades, and its stimulation of DNA damage, tumor formation, mitochondrial dysfunction, and apoptosis is beyond any doubt [28] [29]. For Review see [30]. Upon the EMF-induced increase of the cellular $\mathrm{Ca}^{2+}$ concentration a chain of actions may be triggered that cause deleterious and adverse effects, as has been uncovered by analysis of the mechanistic background provided by a series of publications which all centered on the increase of intracellular $\mathrm{Ca}^{2+}$ as disclosed in the literature cited e.g. in [31].

In numerous papers the authors described that EMFs triggered $\mathrm{Ca}^{2+}$ influx mostly occurs through VDCC [27], and considered positive charges in amino-acid side chains as sensors of EMFs in such channels proteins within the lipid environment of the plasma membrane, and it was concluded that changes by EMFs could trigger an activation of the voltage sensor which is known to control the opening of these channels. This mechanistic proposal is represented in the left scheme of Figure 1. By EMF-induced conformational modification such channels switch to the open state and enable $\mathrm{Ca}^{2+}$ to flow along the large concentration gradient from the outside into the cell. Based on the selectivity and efficacy of various pharmacological inhibitors, most of the analyzed channels were identified as L-type VDCC. The resulting brief elevations of intracellular $\mathrm{Ca}^{2+}$ levels were sufficient to elicit a cell-specific signaling response. Typically, the $\mathrm{Ca}^{2+}$ signal appeared as concentration spike and reached the basal $\mathrm{Ca}^{2+}$ concentration before the process was evoked again. An innovative finding of Pilla [32] was that $\mathrm{NO}^{*}$ formation, which was measured electrochemically by an $\mathrm{NO}^{*}$ electrode, could be detected as early as 5 - $10 \mathrm{~s}$ after beginning of the EMF irradiation. Therefore he postulated the activation of nitric oxide synthase (NOS) as a secondary event since both constitutive NOSs are Ca-dependent. The released NO activated in turn the guanylyl cyclase, and cGMP kinases followed with $\mathrm{Nfr2}$ as final target [33]. The activation of antioxidant enzymes could be induced by this pathway as appropriate response to counteract oxidative stress which is caused by peroxynitrite as product of the recombination of $\mathrm{NO}^{*}$ with superoxide. As mentioned above, peroxynitrite is able to block oxidatively the thiol groups of the Ca-ATPase. This process inhibits the ion pump and leads to a further increase of intracellular $\mathrm{Ca}^{2+}$ and eventually to pathological effects via mitochondrial dysfunction. According to Pall the postulated activation of the VDCC voltage sensor is based on the assumption of a millionfold enforcement of the electric charge effects in the membrane environment. In view of the very low electric fields acting on cells this assumption may be a point of criticism on the proposed mechanism. Nevertheless, the commonly detected EMF-induced $\mathrm{Ca}^{2+}$ influx remains as established fact.

A paper published by Friedman et al. [34] disagreed with the hypothesis of Pall who did not address the source of the required superoxide or the reactive oxygen species (ROS) derived therefrom. This question was assessed experi- 
mentally by Friedman and collaborators, who established that a chain of biochemical events led to an activation of extracellular receptor kinases (ERK) by phosphorylation. A corresponding mechanistic proposal is represented in the right panel of Figure 1. Using pharmacological and chemical inhibitors these authors held a plasma-membrane associated NADH oxidoreductase (PMOR) responsible for the ROS formation. In HeLa cells, which they used in their experiments, it was suggested to be $\mathrm{H}_{2} \mathrm{O}_{2}$, since it was shown that $\mathrm{NADH}$ is oxidized aerobically to $\mathrm{NAD}^{+}$by enzymes localized in the plasma membrane. As a control it was demonstrated that levels of $100-200 \mu \mathrm{M} \mathrm{H}_{2} \mathrm{O}_{2}$ were able to initiate ERK phosphorylation. It was argued that $\mathrm{H}_{2} \mathrm{O}_{2}$ would activate a matrix metalloproteinase that cleaves the $\mathrm{Hb}$-epidermal growth factor (EGF). This process has a stimulating effect on the EGF receptor and subsequently on ERK [35]. These data are well documented, and the frequencies, intensities and exposure times chosen were close to typical mobile-communication exposure and demonstrated

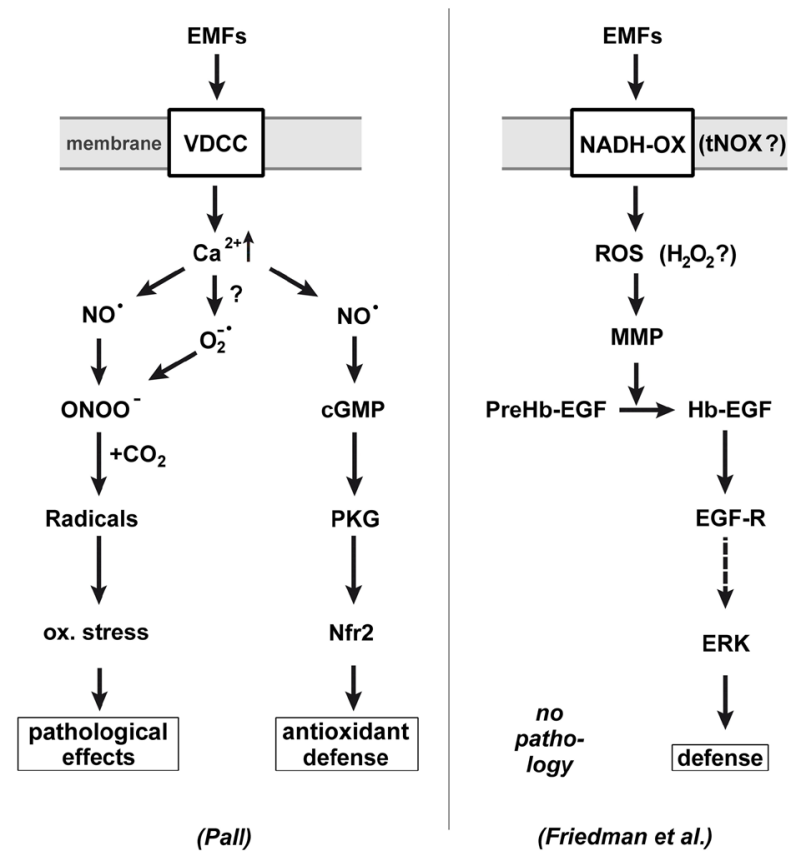

Figure 1. Comparison on two proposed mechanistic concepts that describe the effects of EMFs on cell membranes. Left panel: Model of Pall [27]. The voltage-dependent Ca channel (VDCC) is assumed to be the sensor of EMFs. Two different pathways of responses are expected: 1) an antioxidant defense by which $\mathrm{Ca}^{2+}$ entry causes $\mathrm{NO}^{*}$ production which in turn triggers a chain of enzyme activities including cyclic guanosine monophosphate release (cGMP), cGMP-dependent protein kinase (PKG), and NFE2-related factor 2 (Nfr2). 2) Pathological effects generated by the initial NO* release causing the production of further radicals. Right panel: Model of Friedman et al. [34]. EMFs affect the $\mathrm{NADH}$-oxidase (NADH-OX) which was in case of their experiments a tumor associated $\mathrm{NADH}-\mathrm{OX}$ (tNOX). This leads to the production of reactive oxygen species (ROS), probably $\mathrm{H}_{2} \mathrm{O}_{2}$, that activates the matrix metalloproteinase (MMP) and subsequently the heparin-binding epidermal growth factor (HbEGF), the epidermal growth factor receptor (EGF-R) and eventually the extracellular-signal regulated kinase (ERK), thus provoking cellular defense mechanisms. 
that the two investigated tumor cell lines responded in a non-thermal way by defined mechanisms, albeit the authors missed to include an EMF sensor that triggered the NADH oxidase as a initiating mechanism for the experimentally well documented phosphorylation cascade. No pathology was associated with the proposed ERK pathway in [34].

Taken together, both mechanistic approaches to explain EMFs-induced responses refer to two different signaling pathways that are able to allow cells to cope with an oxidative challenge that has been postulated as main event following exposure to EMFs. Cellular repair pathways originate either from ERK signaling or NO synthesis, and both constitute a physiological response which is not hazardous to cells. Instead, cells and organs may become more resistant to further challenges and could respond favorably towards continuing oxidative stress conditions. This would be a beneficial consequence of EMFs exposure which is in line with the long-known healing effects of low-frequency irradiation as mentioned above.

Criticism was expressed regarding the sequence of reactions proposed by Friedman et al. because of the unspecificity of diphenylene iodonium (DPI) as inhibitor for NADH oxidase [27] [36]. Otherwise Morré [37] described the NADPH oxidase of the plasma membrane as a specific target of DPI and this activity is also part of the plasma membrane electron transport system. Related to the hypothesis of Friedman et al. a main issue of concern is that the nature of a required EMF sensor was not addressed. The $\mathrm{NADH}$ oxidase would have to act as a EMFs sensor but it has not been explained with this function. Moreover, $\mathrm{H}_{2} \mathrm{O}_{2}$ concentrations of at least $100 \mu \mathrm{M}$, which are necessary to activate the matrix metalloproteinase (MMP), appear to be too high under physiological conditions and probably will not be built up by the NADH oxidase activity available in normal cells. According to the literature MMP-2 is effectively activated by peroxynitrite [38]. It is noteworthy to mention that in tumor cells, as used in Friedman's study, the process of "reprogramming" affects glucose metabolism and redox equilibria in a dominant way as pointed out later. It is specific to tumor cells such as HeLa cells to exhibit PMOR activities higher than in normal cells which are under control of growth hormones [39]. As will be shown below, the PMOR may indeed play a role, but by a different mechanism.

The positive and beneficial effects of EMFs are lost, however, upon prolonged challenge that causes enhanced $\mathrm{Ca}^{2+}$ influx and subsequently stimulated $\mathrm{NO}^{*}$ formation. There are several sources from which superoxide could be provided under conditions of repetitive EMFs challenge. One is the exhaustion of the reductant tetrahydrobiopterin that elicits an oxidase function of the NOS [40]. Second, NO is known to block Complex IV of the respiratory chain in mitochondria, and the resulting electron overflow is redirected to oxygen and yields in the formation of $\mathrm{O}_{2}^{-}$[41]. Upon a steady increase in $\mathrm{O}_{2}^{-}$, it will combine with $\mathrm{NO}^{*}$ and the resulting product $\mathrm{ONOO}^{-}$reacts with an excess of $\mathrm{NO}^{\bullet}$ and gives rise first to a nitrosating species (like $\mathrm{NO}^{+}$) until equal amounts of $\mathrm{NO}^{\circ}$ and 
$\mathrm{O}_{2}^{-}$radicals are generated and $\mathrm{ONOO}^{-}$formation remains at a steady state level [42]. It is important to recall that the critical oxidant peroxynitrite will prevail only as long as NO' is not present in excess [43].

In summary, when EMFs are applied only for short exposure periods, the induced $\mathrm{Ca}^{2+}$ influx leads to NO radical production that will be even beneficial since it counteracts Ca-induced cellular activation [44]. Prolonged exposure leads, however, to oxidative-stress conditions which can be compensated by the cellular antioxidant defense systems only up to a certain level, whereas high and continuing EMF applications are able to provoke deleterious effects such as DNA damage, lipid peroxidation, mitochondrial dysfunction and apoptosis. This noxious outcome is depicted in Figure 1 (left panel) in which the dual pathways of $\mathrm{Ca}^{2+}$ influxes are visualized that may result in positive and negative effects on cell survival.

\subsection{VDAC as a New Origin of EMF-Induced Effects}

Our survey of the available literature data was assigned to provide new insight into the interaction of EMFs with cells and will allow a better understanding of the molecular mechanism triggered by EMFs in biological systems. The prominent result is an unexpected involvement of voltage-dependent anion channels (VDACs) in the plasma membrane and their functional association with sensor proteins as mediators of EMFs.

As outlined above, EMF effects through $\mathrm{Ca}^{2+}$ entry via VDCC seem to be well established for excitable cells. The question is, however, whether this entry pathway for $\mathrm{Ca}^{2+}$ is true also in non-excitable cells. In the experiments of Friedman et al. [34] with isolated HeLa cell plasma membranes an irradiation resulted in a more than twofold amount of NADH oxidation compared to control cells. Considering that NADH oxidase could be a target of EMFs as well, we scrutinized the literature on NADH oxidase and PMOR activity. The result was at first a complex and even confusing pattern of redox-active components and suggested the involvement of activating metabolic pathways [45] [46]. Several flavoproteins are engaged in the transfer of hydrogen from NADH and NADPH [47] [48]. One of these proteins uses ubiquinone (CoQ) as acceptor and generates a pool of ubihydroquinone within the plasma membrane. This compound seems to be linked to the generation of a proton gradient by expelling protons to the outside of the plasma membrane upon oxidation. Potential electron acceptors for reduced CoQ could be dioxygen as postulated by Friedman in the phosphorylation cascade that leads to the formation of $\mathrm{H}_{2} \mathrm{O}_{2}$. A second system was reported to reduce a b-type cytochrome but also a $32 \mathrm{kDa}$ copper protein with sequence identity to VDAC of the outer mitochondrial membrane [49], where it has an important function for cytochrome c release by formation of "megapores" as a consequence of mitochondrial dysfunction and apoptosis [50]. The fact that VDAC is expressed in the plasma membrane is known for a long time [45] [51]. There it is part of the PMOR system and has the ability to reduce ferricyanide 
that was provided as artificial electron acceptor [52]. The extra-mitochondrial location was verified by detection of a leader sequence for transport into the plasma membrane [53] and by isolation as part of caveolae [54]. Physiologically it is able to reduce diferric transferrin and releases ferrous iron to be taken up in the cell where it is reoxidized and stored in ferritin [52] [55]. Semidehydroascorbate is another acceptor that is reduced by one-electron reduction to ascorbate, and thus can be recycled as antioxidant [56] [57]. Several isoforms of VDACs were identified that have different reactive sulfhydryl groups [58], but at least two sulfhydryl groups are conserved in all isoforms and may serve in thiol-disulfide exchange [59]. Surprisingly, the redox activity of VDAC is controlled by growth hormones [60], and even more interesting, transformed tumor cells have expressed a different NADH oxidase (tNOX) and a different VDAC (VDAC2) [61]. For this reason HeLa cells as used by Friedman et al. may not be representative for NOX/VDAC mediated activities. In summary, HeLa cells, like most cancer cells, are clearly distinct with regard to the plasma membrane electron-transport system, which may contribute to their autonomous growth capability.

In view of such complex functional properties, the common isoform, mitochondrial VDAC1, was cloned and expressed for detailed biophysical and biochemical investigations. It was characterized as a beta barrel membrane protein with six membrane spanning domains [62]. High resolution NMR and molecular dynamics calculations discovered that glutamate 73 is a very flexible and mobile residue, which is exposed in lipid micelles to the fatty-acid moiety and showed a fast protonation/deprotonation equilibrium with dynamics in the $\mu$ s to ms time range [63]. This was considered to be important since this glutamate residue was found to be crucial for binding of hexokinase- 1 in the deprotonated state and for a condition that provided stability to the anion-selective resting state of VDAC. In the case of the mitochondrial VDAC an attachment of hexokinase- 1 was found and associated with an augmented supply of NADH in the glycolytic pathway [64]. The same applies for NADPH formation by the pentose-phosphate cycle needed for NO` synthesis. Interestingly, also NOS was associated with VDAC [65].

Investigations of the electrophysiological behavior of VDACs [66] provided intriguing new aspects on an EMF-induced $\mathrm{Ca}^{2+}$ influx into cells. It is known that VDAC in the cell membrane exists in a high-conductance anion selective state in which it is able to transfer ATP out of the cell [67] [68], which is its major physiological function as channel. At membrane voltages $<-20 \mathrm{mV}$ a "multiple states" condition exists, in which "open" $\left(\mathrm{Cl}^{-}\right.$conducting) and "closed" $\left(\mathrm{Ca}^{2+}\right.$ conducting) states existed simultaneously [66]. Studies of its voltage dependence in the range of -40 to $+40 \mathrm{mV}$ reported transitions between different low-conductance substates with selectivity for small cations and a further transition to a cation-selective state of high conductance [69] [70]. Upon a monotonic voltage increase from -40 to $+40 \mathrm{mV}$ it was found that at $-10 \mathrm{mV}$ the low con- 
ductance cation selective state of VDAC could be transformed to a large conductance anion selective state. When the voltage was increased above $+20 \mathrm{mV}$, another transition was observed to a selective state of large cation conductance. Other conductance changes were found between -30 to $-40 \mathrm{mV}$. Studies of the channel properties of VDAC in membranes from mitochondria as well as from plasma membrane and in reconstituted planar lipid bilayers revealed by electrophysiological experiments that transitions between at least three different states occurred between an anion transporter, a $\mathrm{Ca}^{2+}$ channel with low conductance and even a megapore that allowed massive $\mathrm{Ca}^{2+}$ and possibly also $\mathrm{Cl}^{-}$influxes [71]. Under electrophysiologically undisturbed conditions, i.e. at the resting potential, the preferential functional state of VDAC is an ATP transporter with an outward-directed flux.

In excitable cells action potentials will evoke short $\mathrm{Ca}^{2+}$ influx spikes through VDAC only if it is in the $\mathrm{Ca}^{2+}$-conducting so-called "closed" state. Upon persisting depolarizing conditions (several ms) VDAC promotes $\mathrm{Ca}^{2+}$ influxes, and those depolarizations may cause pathologic $\mathrm{Ca}^{2+}$ influxes and eventually $\mathrm{Ca}^{2+}$ overload of the cell [72] [73] [74]. This causes in turn oxidative stress as depicted in the left scheme of Figure 1.

VDAC in the outer mitochondrial membrane shows an analogous behavior which is well documented [75] [76]. Especially the transition to the megapore, known as permeability transition, marks a crucial step towards apoptosis [77], when cytochrome $\mathrm{c}$ is released through mitochondrial aggregated VDAC into the cytosol and activates the apoptosis-inducing factor (AIF) and caspases [78]. In contrast to the cell membrane, however, changes of the membrane potential of the outer mitochondrial membrane are considered of minor relevance, and thus have found only limited attention in the published literature [79]. Therefore, our focus was set on the literature on VDAC in the plasma membrane and on the question whether and how EMFs are able to trigger a mechanism that promotes transitions into states which are able to explain the observed graded $\mathrm{Ca}^{2+}$ influx.

Electrophysiological experiments on channel properties of VDAC in mitochondrial and plasma membranes or reconstituted in black lipid membranes were performed to study the three different ion-conducting states (Figure 2). In the "open" conformation the channel is anion selective. In the "closed" state larger anions are excluded but cations are well permeable, and a distinct conductance for $\mathrm{Ca}^{2+}$ was detected. Due to its role as second messenger, the basal $\mathrm{Ca}^{2+}$ concentration in the cytosol is about $100 \mathrm{nM}$, but outside the cell in the order of millimolar and in the mitochondrial matrix between $20 \mu \mathrm{M}$ (physiological condition) and $500 \mu \mathrm{M}$ ( $\mathrm{Ca}^{2+}$ load) [80] [81]. Across the VDAC-containing mitochondrial and plasma membrane the electrochemical potential gradients are always directed towards the cytosol and facilitate in the Ca-conducting state a $\mathrm{Ca}^{2+}$ influx into the cytosol. Studies of the voltage dependence of VDAC revealed that the open probability decreases from about 1 at a membrane potential of zero 
to about 0.5 at typical membrane potentials of $-40 \mathrm{mV}$ to $-60 \mathrm{mV}$ in the case of non-excitable cells [66] [82] [83]. In the open and preferably anion-transporting state of VDAC the $\mathrm{Ca}^{2+}$ conductance is less than $4 \%$ of the ion flux. In the so-called "closed" state at (positive or negative) membrane potentials the anion conductance is significantly decreased while the $\mathrm{Ca}^{2+}$ conductance is amplified (especially at negative potentials) by a factor of 4 to 10. Extrapolating from experimental results [66] and accounting the probability of the Ca-conducting state, under an assumption of $1 \mathrm{mM}$ extracellular $\mathrm{Ca}^{2+}$ about $20.000 \mathrm{Ca}^{2+}$ ions would flow per VDAC and per s into the cytosol. To balance this influx in order to maintain the physiologically required low basal concentration, the cell possesses active transporters such as the plasma membrane $\mathrm{Ca}$-ATPase and the $\mathrm{Na}, \mathrm{Ca}$ exchanger. If their outward transport capacity is not sufficient in the case of so-called $\mathrm{Ca}^{2+}$ spikes, finally mitochondria will act as buffer storage compartments to secure rapid recovery of the basal $\mathrm{Ca}^{2+}$ concentration in the cytosol. If, however, an elevated $\mathrm{Ca}^{2+}$ influx persists, the mitochondrial storage capacity runs out, the high $\mathrm{Ca}^{2+}$ concentration inside the mitochondria induces VDAC closure of the anionic state and converts to the cationic substate, which prepares the way to apoptosis [66].

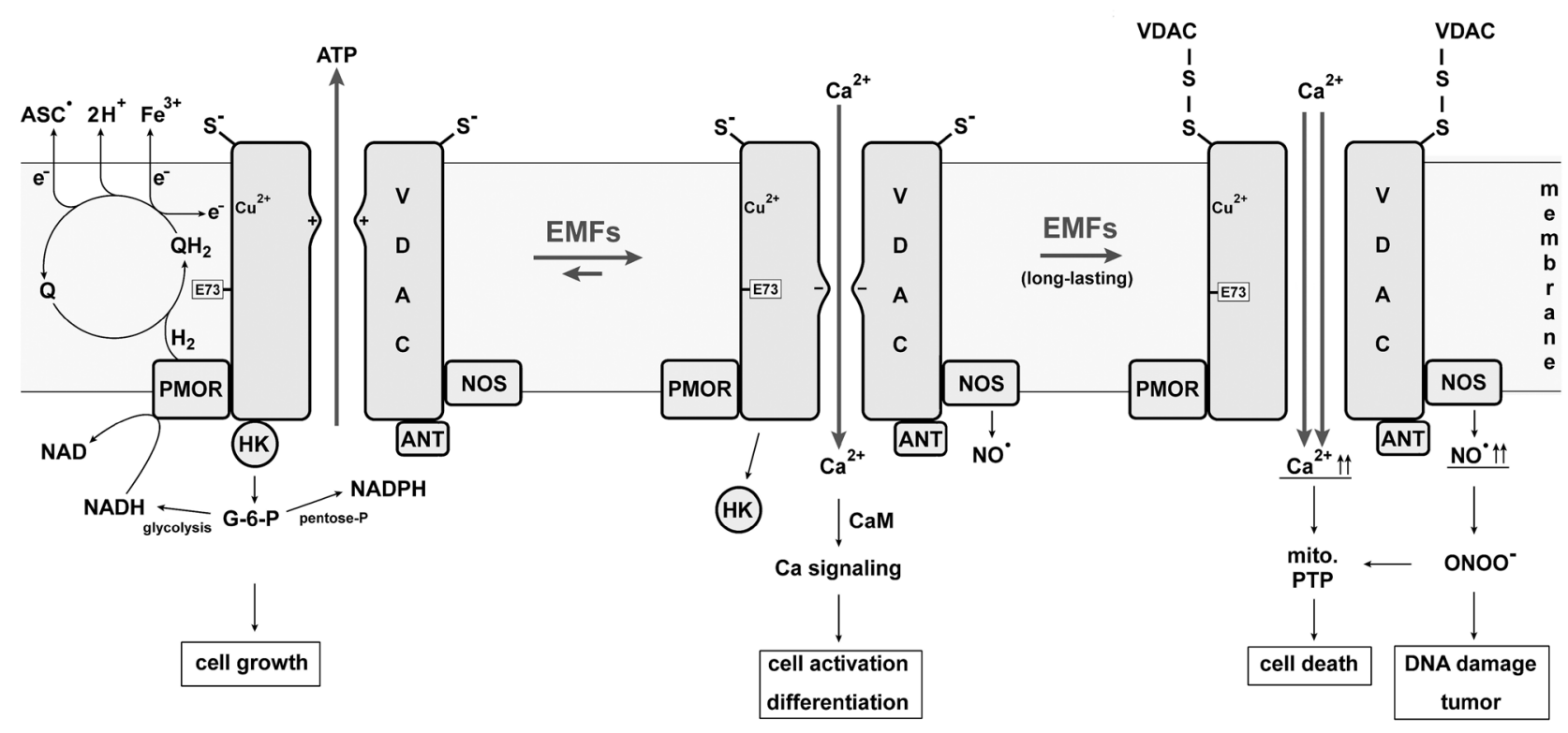

Figure 2. Schematic representation of the different functional states of VDAC in response to EMFs. Left panel: Under physiological conditions the high-capacity anion selective state is prevalent, named "open state". The protein complex consists besides VDAC of several enzymes: plasma membrane oxidoreductase (PMOR) which consists of TSPO and a flavoprotein, hexokinase1 (HK), adenine nucleotide transporter (ANT), and NO-synthase (NOS). The complex is also coupled to an electron-transport system based on ubiquinone, CoQ (Q). The extracellular electron acceptor is a semidehydroascorbate (Asc). Middle panel: Low-capacity cation-selective state, named (misleadingly) "closed" state. The conserved glutamate (E 73) affects a major conformational change to a cation (including $\mathrm{Ca}^{2+}$ ) selective state and $\mathrm{HK}$ dissociation. The transition into this state may be promoted or stabilized by EMFs contrary to the physiological needs of the cell. Right panel: A high capacity cation-selective state, named "mega pore", is formed upon a prolonged unphysiological condition in the cell and allows high $\mathrm{Ca}^{2+}$ fluxes into the cytosol, which activates subsequently the mitochondrial permeability transition pore (MitoPTP) inducing cell death by apoptosis. Oxidative oligomerization of VDAC under this condition is indicated by "VDAC-S-S-". 
Another important detail of VDAC is the presence of a conserved negatively charged amino acid. According to NMR data glutamate 73 is buried in the hydrophobic core of the phospholipid bilayer and calculations on the flexibility within the beta strands 2 to 7 increased with the negative charge on the glutamate 73 [67]. Even a perturbation of the membrane polar head groups was postulated from MD simulations pointing to a local thinning of the membrane [67].

$\mathrm{Ca}^{2+}$ influxes into the cell, permitted not only by VDAC but also by other VDCC, which are carefully balanced by active export, may be enhanced due to various reasons, be it mechanical injuries, noxious chemical compounds and also EMFs. As already mentioned above, a common initial event observed in cells exposed to pulsed EMFs is an elevated cytoplasmic $\mathrm{Ca}^{2+}$ level in the cytosol. Based on the experimental findings presented above, VDAC is an appropriate candidate as primary target being affected by pulsed EMFs. Since its distribution between open and closed states can be modulated by the membrane voltage (and therefore named "voltage-dependent anion channel"), the protein must possess a voltage sensor, although it has not yet been identified conclusively so far [84]. Basic physical properties require, however, inevitably the existence of electric charges that interact with the electric field and transmit changes of the electric field into functional responses. At appropriate frequencies even minor changes of the electric field seem to be able to affect the charge distribution within the protein and thus modify the pattern between the open and closed state of VDAC.

It is evident that electromagnetic waves in the $\mathrm{GHz}$ range are too fast by orders of magnitudes to evoke motions of amino-acid side chains or protein domains. Pulsed EMFs with various frequency patterns up to $1000 \mathrm{~Hz}$ are, however, suitable candidates, which are able to transfer energy absorbed by charged structural components in the protein that may be amplified, when provided in a fitting (resonance) frequency window, and thus evoke transitions into specific conformational states. A proposal of a possible molecular mechanism that causes enhanced $\mathrm{Ca}^{2+}$ influxes through VDAC is based on the assumption that suitable frequencies in the pattern of pulsed EMFs stimulate the transition to and/or cause a stabilization of a Ca-conducting state of the channel.

Therefore, we recommend to perform experimental studies with various cell species to analyze the resulting cytoplasmic $\mathrm{Ca}^{2+}$ concentrations as function of the pulse frequencies in the (commercially used) range between 6 and $1600 \mathrm{~Hz}$. An effect of pulsed EMFs on the behavior of the membrane inserted VDAC may be assessed experimentally by patch clamp technique with cells or model membranes. Another option would be the use isolated cells or cultured cells together with intracellular fluorescent indicator dyes to detect in real time $\mathrm{Ca}^{2+}$ uptake upon exposure to user-defined EMF protocols. The results of such studies may answer the pertinent question of whether and how exposure to EMFs is able to affect the function of VDAC. This may occur either via modifications of the membrane potential that affects the whole protein or by interaction with specific protein domains or single amino-acid side chains such as the negatively charged 
glutamate 73. Even a rise or collapse of a proton gradient across the membrane could influence the ionization state of this critical residue. Interactions with proteins in functional contact with VDAC may contribute in addition (Figure 2) as will be discussed in the following paragraph. In essence, VDAC possesses all properties required to act as sensor of electromagnetic signals.

\subsection{VDAC and the $18 \mathrm{kDa}$ Translocator Protein}

One of the proteins that interacts closely with VDAC is known as the $18 \mathrm{kDa}$ translocator protein (TSPO), earlier named benzodiazepine receptor (BR) since it binds psychoactive drugs of this group with high affinity [85]. Benzodiazepines are among the most extensively studied drugs because of their antidepressant, anxiolytic and anticonvulsive properties. Detailed Reviews are [86] [87]. TSPO is primarily located in the outer mitochondrial membrane of many peripheral tissues and has been named PBR to discern it from the central benzodiazepine receptor, CBR, found preferentially in neurons [88]. Both proteins are similar in sequence and possess five membrane-spanning domains but differ in their binding affinities to a variety of pharmacological ligands with psychoactive impact [86]. Surprisingly, their physiological mode of action is not well defined although tight binding of cholesterol and porphyrins indicated a role in steroid and heme biosynthesis until observations with knock-out mice have challenged an essential role in both pathways [89]. PBR was found to be associated with activated glia cells and microglia in brain, and by in vivo use of diagnostic ligands this fact is now used to locate inflamed areas caused by brain tumors or neuropathological events [90].

An early report on CBR location on the plasma membrane of neurons stirred our attention [91]. The finding that CBR might occur in connection with VDAC and form a functional entity as part of the PMOR complex fueled our hypothesis that VDAC is involved in this complex as $\mathrm{Ca}$ channel. With respect to the fact that in neurons CBR in the PMOR complex could be the target of psychoactive drugs is intriguing since the symptoms of electromagnetic hypersensitive persons can be associated with dysfunctionalization of neurons and the well-known relieving effects of benzodiazepines.

A mechanistic link became apparent when the sequence of benzodiazepine receptors was analyzed and compared with other TSPO-like proteins. They fell into the category of "tryptophan-rich proteins" which are characterized by a triad of Trp residues that also occur in photolyases [92] [93] [94] [95] and cryptochromes [92] [96]. These enzymes have blue-light receptors that use light to trigger an internal redox reaction in which a triplet state converts into two radicals that form by electron hopping across two Trp-residues a tryptophanyl radical on the last one of the triad [93]. The resulting spatial separation of two unpaired spins prevents a short term relaxation to the ground state and allows distinct chemical reactions, e.g. with oxygen. Such reactions can be affected by a magnetic field which affects the product pattern. This behavior imparts such 
enzymes properties of a magnetosensor [97] if different products result in the presence and absence of magnetic fields such as superoxide or hydrogen peroxide. Reports in the literature assign orientation of birds in the geomagnetic field of about $50 \mu \mathrm{T}$ to the presence of cryptochromes, in which a flavin absorbs blue light and enters a triplet state. In presence of a neighboring Trp residue this state converts to a tryptophanyl-flavin-radical pair [98]. Electron/proton tunneling allocates the electron on the last Trp of the triad and this spatial charge separation leads to an increased lifetime of the two radicals. Their subsequent decay can be affected by a magnetic field and possibly leads to different chemical decay pathways [99]. This mechanism was considered as basis for orientation control of migrating birds in the geomagnetic field [92].

Applying this concept to the TSPO proteins with their similar structural components and allows the suggestion of an interaction with electromagnetic fields. Radical formation would not be facilitated by light but by NADH oxidation with oxygen as acceptor which is a potent source of energy and redox activity. Radical intermediates could be easily formed and be part of a magnetoreceptive radical system comprising two electrons or even three as recently proposed [97].

In conclusion, additionally to the presence of the sensor of the electric field by VDAC, the TSPO/CBR complex may provide in a concerted way a supporting and synergistic role as magnetosensor responding to the magnetic field component of EMFs. In such a combined effort even low-intensity EMFs could be monitored by the TSPO/VDAC complex due to the combined absorbed energies from electric and magnetic fields and could amplify a promotion or stabilization of the Ca-conducting substate of VDAC.

Such a device could even act as transformer of information from domain-overlapping brain waves to $\mathrm{Ca}^{2+}$ pulses in single cells. To our knowledge the molecular mechanism for converting the information (i.e. energy) of such electromagnetic waves into chemical signals still awaits elucidation.

\subsection{The PMOR/TSPO/VDAC System in Erythrocytes}

In numerous published studies the function of the plasma membrane oxidoreductase could not be well separated from the various activities of the redox components in the mitochondrial membrane due to the used experimental approach. Investigations with erythrocytes are less complicated since they are devoid of mitochondria, and hence electron transport in the plasma membrane can be studied without distortive interference. In addition, red blood cells (RBC) do not grow, and therefore, are unaffected by growth factors that normally control part of the PMOR activity [60].

Although erythrocytes appear to be glycolysis-driven empty membrane envelopes, their plasma membrane is highly complex. It contains all components of the PMOR system such as flavoproteins, ubiquinone pool, TSPO and even three kinds of VDACs [100] [101] [102]. Electron acceptors are ferricyanide, oxidized ascorbate, and with low activity oxygen. In combination with ANT, VDAC is 
able to export ATP. This process was found to be mediated by prostacyclin in a PKA-dependent pathway, and the released ATP constitutes a physiological relaxation of smooth muscle for better oxygen supply in the blood vessels [103]. These facts point to the presence of a pronounced anion-selective VDAC activity.

Erythrocytes are non-excitable cells with a resting potential of $-10 \mathrm{mV}$ [104], suggesting that transitions into the Ca-selective substates of VDAC are possible. Since the VDAC protein in the RBC is identical to the well-studied VDAC1 in mitochondria, this has to be expected and was indeed observed [105]. By stimulation with the TSPO ligand Ro5-4864 the $\mathrm{Ca}^{2+}$ influx was enhanced about fourfold, and the increase was blocked by the VDAC inhibitor Bcl-XLBH4 [106]. A hundred channels per cell were probably enough to produce a $\mathrm{Ca}^{2+}$ influx sufficient to modify the properties of the cell membrane which led to the characteristic aggregation behavior of erythrocytes [107] as it was observed upon exposure to EMFs. This phenomenon is called "rouleaux" or coin-roll formation and constitutes the physiologically needed stacking of RBC which helps the cells to move through narrow capillaries for oxygen supply in peripheral blood vessels [108]. The enzyme lipid scramblase has distinct affinity for $\mathrm{Ca}^{2+}$ and is able to flip phosphatidyl lipids from the inner surface of RBC to the outside which may promote the agglutination during coin-roll formation [109].

Coin-roll formation was observed already early with mobile phone users and was proposed even as a simple test for EMFs effects on living cells [110]. It would be worthwhile to investigate experimentally the sequence of events postulated above and possibly re-establish RBC agglutination as a sensitive test for non-thermal EMFs interactions. For quantitation this effect might have restrictions since the process is reversible and may be enforced by the activity of the Ca channels, Piezo1/2, which contribute with pressure-induced and membrane-potential dependence $\mathrm{Ca}^{2+}$ influxes [111].

There are more pathways of $\mathrm{Ca}^{2+}$ influx into $\mathrm{RBC}$ that lead eventually to $\mathrm{Ca}^{2+}$ overload [104] [111]. While other cells would respond with apoptosis, this cannot occur in RBC due to the lack of mitochondria. In RBC, however, an equivalent to apoptosis, called eryptosis, was observed which is characterized by Ca-induced activation of the Gardos channel that allows the extrusion of $\mathrm{K}^{+}$and $\mathrm{Cl}^{-}$and results in shrinking and collapse of the erythrocyte structure as is seen in clot formation [108]. Aggregation of VDAC and TSPO to corresponding dimers or higher polymers was observed in RBCs under such stress conditions. This suggests a similar role for the VDAC/TSPO complex as in mitochondrial megapore formation during apoptosis [112].

Erythrocytes used as a model system to study EMF interactions with living cells may more definitely proof the important role of NO` production as one of the first impacts of $\mathrm{Ca}^{2+}$ influx. The presence of NOS in the plasma membrane of RBCs has been established even though $\mathrm{NO}^{*}$ released to the cytosol may be trapped as nitrate upon reaction with oxyhemoglobin [113]. When released to the outside $\mathrm{NO}^{*}$ acts as a potent vessel relaxant through stimulation of G-cyclase 
in the cells of the vascular wall. Under hypoxic conditions deoxyhemoglobin will be present that converts nitrite to NO* with the same dilation-inducing effect on vessels, which leads in turn to improved oxygen supply. Such positive features of NO ${ }^{*}$ will be eliminated by superoxide since it promotes formation of peroxynitrite which was held responsible for oxidative stress and the accompanying negative impact of $\mathrm{Ca}^{2+}$ overflow as well as inducing the pathway to apoptosis. Since mitochondria are absent in RBCs the source for superoxide should be related to the PMOR system in the cell membrane using NADH or NADPH for oxygen reduction to $\mathrm{O}_{2}^{-}$. (In this respect it is noteworthy to mention that in mitochondria $\mathrm{NO}^{*}$ is inhibitory to the formation of the megapore [44] and triggering apoptosis. This property could be noted as another positive effect of $\mathrm{NO}^{-}$that is abrogated by superoxide. The always neglected source of this radical in the PMOR system could be highly significant in redox regulation.)

\subsection{Psychological Disorders and Autism}

Finally an interesting aspect of human psychology should be mentioned by consideration of the TSPO/VDAC complex as mechanistic interface between EMFs and neuronal responses. Based on medically well accepted psychological disorders of electromagnetic hypersensitive persons in form of insomnia, unrest, burn-outs, or cognitive and memory deficits, possible explanations will involve necessarily the complex subject of brain physiology. This starts with the biophysics of brain waves and ends in the biochemistry of NMDA or GABA receptors. Significant advances in understanding were achieved by studies on the mechanisms of sleep control in Drosophila where a complex network from different brain waves controls the activity of interwoven receptors [114]. To gain insight into kinesic behavior a neuronal oscillation code could be established in which coupling of $\mathrm{Ca}^{2+}$ spiking with gamma and theta oscillations plays a dominant role [115]. Brain information systems seem to be built up by microcircuits of electrical and magnetic impulses, and it became challenging to find out whether external EMFs are able to disturb the internal communication. On the background that on one hand diazepines bind to CBR with high affinities and on the other hand diazepines are able to repair deficits in psychiatric brain disorders, a connection between both findings may be considered. A discussion of more details which were published in the pharmacological literature is, however, outside the scope of this contribution.

Based on considerations of the molecular components known to be affected by EMFs, an impact of EMFs on the development of autism in childhood cannot be excluded [116]. A possible hint on such a connection may be deduced from statistical data reflecting the observation of an exponential increase of reported cases of autism in children during the recent thirty years [117].

Clinical findings were reported that antibodies against VDAC and hexokinase were frequently identified in autistic children [118]. Both antibodies inhibit the function of VDAC and hexokinase. Additionally, it is known that VDAC anti- 
bodies impair growth and induce apoptosis in neuroblastoma cells in culture [119] [120]. Thus, a kind of autoimmune effect may develop against VDAC and result eventually in brain activity affected in the grown-up organism. In autistic children enhanced $\mathrm{NO}^{\circ}$ metabolites and increased glutathione peroxidase activity were detected, and these observations point to a moderate chronic inflammation [121]. Therefore, a primary effect of EMFs on the function of VDAC in embryonic tissue may be a disturbance of the equilibrium of differentiation and apoptosis that controls embryonic cell development. Another connection of the TPSO-VDAC system and autism was reported in a study by Crane et al. [122] that highlighted the significance of its upstream redox partners, ubiquinones. Reduced ubiquinone serves as reductant for VDAC with its copper center and reactive thiolate residues. When in control experiments ubiquinone was extracted with organic solvents, the reduction of ferricyanide, used as artificial electron acceptor, was diminished for the most part but was restored by addition of ubiquinone. In a clinical trial the authors supplied reduced ubiquinone to autistic children at a daily dose of $50 \mathrm{mg}$ over a three-month period and found significant improvements in verbal communication, playing games, sleeping and reduced food rejection. Plasma CoQ levels increased during the time of treatment by almost a factor of five. The sensitivity of NADH-ferricyanide reductase against mercurial compounds is high and a connection of mercury with autism has been repeatedly postulated, which is another joint link between NADH oxidase and autism [123]. In VDAC the thiolate groups are extremely sensitive to mercurials and this property could affect the activities of VDAC. Such effects are independent from the genetic disposition as contributing factor in autism.

In summary we like to propose from such observations that an undisturbed function of the VDAC/TSPO/hexokinase complex in the membrane of neural cells is crucial for the developing brain. When this protein complex becomes a target of antibodies or environmental factors such as toxic agents or EMFs above a crucial threshold, the complex network of neuronal communication within and between different areas of the brain will become increasingly disturbed with the consequence that autism may emerge in the developing brain. In autistic patients smaller sizes of the cerebellum vermis were reported [124]. In adult rats prolonged treatment with clonazepam changed the pattern of brain receptors, especially the subunits of the NMDA receptors, which became reversible after discontinuation of the drug [125]. However, in newborn rats similar treatments led to drug-induced changes in the developing brain that were conserved in adulthood, and increased apoptosis and suppressed neurogenesis were reported. The authors concluded the appearance of possible deficits in behavior later in life.

Based on such mechanistic background it can be proposed that mental disorders may originate from disturbances of the brain electromagnetic network caused by disadvantageous effects on the associated receptors in cell membranes. TSPO in its CBR form certainly plays a major role in this process, since many of the disorders like insomnia or depression can be treated with diazepines of the 
clonazepam type which interact with this enzyme complex. In view of the alarming increase of autism and the well-funded research to study this phenomenon, we consider it is justified to propose that the possible role of CBR in mediating internal and external EMF effects in brain should become subject of future research. Biochemical and histological tests to verify or dismiss a connection are within experimental reach.

\section{Conclusions}

Numerous studies on effects of EMFs in biological systems revealed a multitude of biochemical changes with positive or negative physiological outcome in cells, tissues or the whole organism. Most of such actions can be explained by an influx of $\mathrm{Ca}^{2+}$ into cells as initial event. For electrically excitable cells VDCCs were suggested as possible pathways. For non-excitable cells we found intriguing evidence that VDAC fulfills all criteria of an EMF-controlled Ca channel. This surprising result found its explanation by structural and functional modifications associated with conformational changes of the membrane-bound VDAC. In the outer mitochondrial membrane with a potential around zero the channel transports preferentially anions. VDAC is also found in smaller amounts in cell membranes and this leads to the pertinent and crucial question of VDAC function in the two very different locations.

It is known that VDAC in mitochondria facilitates under physiological conditions mainly ATP release. When $\mathrm{Ca}^{2+}$ overload occurs and/or the proton-motive force ceases and no more ATP is produced, VDAC switches to the so-called closed state in which it releases $\mathrm{Ca}^{2+}$ to the cytoplasm. By further oxidative modifications VDAC is able to form expanded pores by oligomerization. These lead eventually to a permeability transition allowing cytochrome $c$ release as the committing step towards apoptosis.

The role of VDAC in the plasma membrane is elucidated by its role in RBC, which do not possess mitochondria. There the channel is part of the PMOR system, a complex with several other redox proteins, especially TSPO. It catalyzes the reduction of extracellular iron complexes and controls ATP release from $\mathrm{RBCs}$ in a protein A kinase dependent way.

Interestingly, $\mathrm{RBCs}$ responds to mobile phone radiation by rouleaux formation, and this intercellular attachment is likely to be due to a moderate $\mathrm{Ca}^{2+}$ influx. Although only about $100 \mathrm{VDAC} / \mathrm{TSPO}$ channels are present per RBC the $\mathrm{Ca}^{2+}$ influx provides enough $\mathrm{Ca}^{2+}$ in the sub-plasma membrane space to promote aggregation. VDAC is a likely candidate for such a $\mathrm{Ca}^{2+}$ influx, but so far the mechanosensitive Piezo 1 channel cannot be ruled out since it displays also voltage sensitivity [111].

As a summary of the first part of our quest to identify potential targets of EMFs we conclude that VDAC as part of highly sophisticated "transduceosome" has to be considered to be a potential $\mathrm{Ca}^{2+}$ channel with various substates that are formed in response to subtle changes of the membrane potential either in the 
outer mitochondrial or plasma membrane. Physiologically this applies for situations of energy deprivation leading to pro-apoptotic conditions. Under regular conditions the VDAC complex controls substrate supply to mitochondria and ATP export to the cytosol. $\mathrm{Ca}^{2+}$ overload, provoked by longer-lasting elevated $\mathrm{Ca}^{2+}$ in the cytosol, is compensated first by mitochondrial uptake on the expense of the membrane potential and the proton gradient, until VDAC converts to a $\mathrm{Ca}^{2+}$ channel that levels the excess of $\mathrm{Ca}^{2+}$.

Exposure to EMFs causes an additional influx of $\mathrm{Ca}^{2+}$ by enhancing the $\mathrm{Ca}$ channel activity of VDAC either in the plasma membrane or the outer mitochondrial. Resulting elevated $\mathrm{Ca}^{2+}$ levels will be lowered by the various extrusion mechanisms on the expense of energy. Even short pulses may produce $\mathrm{Ca}^{2+}$ spikes that lead to accumulation of $\mathrm{Ca}^{2+}$ in the ER and eventually in mitochondria. Subsequent emergence of oxidative stress relies on secondary events such as NO formation, which are well described in the literature. In case of the erythrocyte membrane we consider VDAC to be the EMF-sensitive channel facilitating sufficient uptake of $\mathrm{Ca}^{2+}$ that leads to a membrane modification with rouleaux formation. Thus, RBCs could become a suitable system to study various aspects of EMF effects. So far no studies on the EMF impact on VDAC in mitochondria were reported in the literature. Since under normal metabolic conditions $\mathrm{Ca}^{2+}$ levels in the cytosol and matrix are low, one would not expect a significant change of the $\mathrm{Ca}^{2+}$ gradient if the mitochondrial VDAC changes to the $\mathrm{Ca}^{2+}$ conductance. Whether ATP or metabolite transport is affected by EMFs remains to be investigated.

In the second part of our study we became aware of the role of TSPO, a protein closely associated with VDAC. It seemed to be more than a carrier for heme and cholesterol as it is suggested in literature, especially since its amino acid sequence contained a Trp triad that is characteristic for the function of magnetosensors in migrating birds. The sensing mechanism requires oxidation of $\operatorname{Trp}$ and stabilization of at least two radicals which decay to different products in dependence of the magnetic field. Interestingly, VDAC possesses NADH oxidase activity and would be able to perform such oxidations in the vicinity of TSPO. The hypothesis of TSPO as a magnetosensor is under investigation.

Published properties of TSPO, which is known to be the benzodiazepine receptor in its peripheral mitochondrial (PBR) and central form (CBR) in neuronal tissue, introduced an interesting new functional aspect. Highly effective pharmacological ligands of CBR are clinically used to treat neurological deficits such as insomnia, burnout or depression, which were observed as syndromes in electromagnetic hypersensitive persons. We have outlined that such characteristic neuronal deficits and their treatment with TSPO receptor ligands suggest a mechanistic connection originating in a participation of TSPO in a disturbed signal transduction by brain waves. This hypothesis can be subject to straight forward experimental verification with a suitable hardware for EMF generation and modification of frequencies, intensities and pulsations. A second piece of 
evidence that VDAC/TSPO may play a crucial role as interface between psychic disorders and EMF exposure became obvious by abundant reports on autism. Pediatric patients exhibited in their blood significant amounts of antibodies inhibiting VDAC and hexokinase1. Accordingly it was already suggested that autism may be classified as autoimmune disease.

Summarizing the second part of our literature search we propose the hypothesis that TSPO acts also as a magnetosensor. In conjunction with VDAC as the sensor for the electric field the specificity and sensitivity of the complex to monitor EMFs would be enhanced, possibly to the extent that brain waves could become detectable by the VDAC/TSPO complex in neuronal plasma membranes. Even this assumption can be tested under the influence including effects of externally applied EMFs.

In essence we suggest that in brain the plasma membrane VDAC/TSPO complex is able to sense brain-derived EMFs but would also be subject of external fields. Their effect would be a strengthening of the oxidative defense systems, under overstimulation, however, a consequence could be a disturbance of information processing especially in developing organisms. This is summarized and depicted in Figure 3.

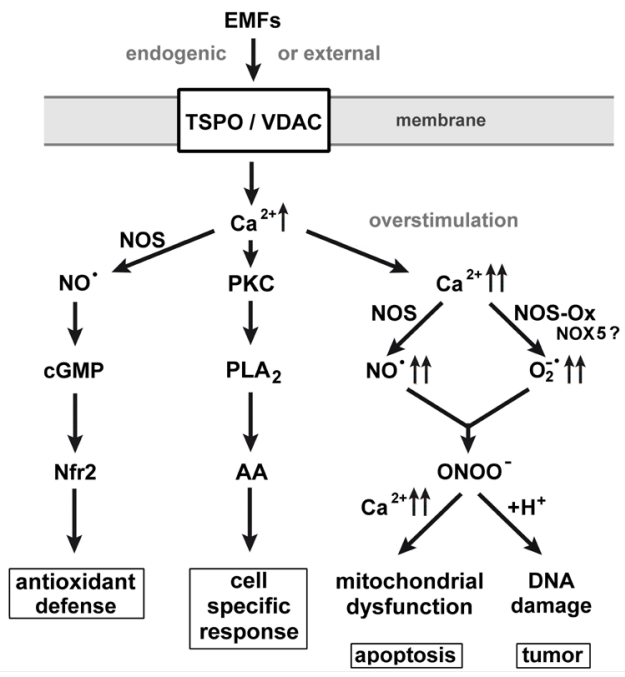

Figure 3. Mechanistic concept proposed in this paper. $\mathrm{Ca}^{2+}$ entry is promoted by the TSPO/VDAC complex in the plasma membrane of cells triggered by EMFs (TSPO: 18 $\mathrm{kDa}$ translocator protein, VDAC: voltage-dependent anion channel). Single EMF pulses (or consecutive pulse with a low frequency that allows recovery of the cytoplasmic $\mathrm{Ca}^{2+}$ concentration in between) evoke an antioxidant defense mechanism identical to the model of Pall (Figure 1, left scheme) or induces cell-specific responses. By the Ca-dependent protein kinase $\mathrm{C}(\mathrm{PKC})$ phospholipase $\mathrm{A}_{2}\left(\mathrm{PLA}_{2}\right)$ is activated that in turn releases arachidonic acid (AA) from lipid cleavage. Repetitive pulses with higher frequencies that lead to continuously enhanced $\mathrm{Ca}^{2+}$ concentration generated by the activity of the $\mathrm{Ca}$ and NADPH dependent NADH-oxidase (NOX5) and the nitric oxide synthase (NOS) high enough concentrations of $\mathrm{O}_{2}^{-\cdot}$ and $\mathrm{NO}^{*}$ which both react to form peroxynitrite $\left(\mathrm{ONOO}^{-}\right)$. This highly reactive molecule leads together with the high $\mathrm{Ca}^{2+}$ concentration to mitochondrial dysfunction and eventually to apoptosis or by protonation yielding $\mathrm{OH}^{*}$ and $\mathrm{NO}_{2}$ radicals 
with subsequent potential for DNA damage and possible tumor formation.

Taken together, there are clearly non-thermal effects of electromagnetic fields on biological systems. We found confirmation of earlier assumptions and obtained additional evidence that $\mathrm{Ca}^{2+}$ influx into cells constitutes a primary event which leads to cell activation. The resulting activity is cell-specific and may comprise diverse outcomes such as enhanced cell motility favoring healing processes or could cause oxidative stress conditions even with DNA damage or cell destruction. We here propose the voltage dependent anion channel as a $\mathrm{Ca}^{2+}$ influx channel under membrane-depolarizing conditions. Considering the association of the $18 \mathrm{kDa}$ transport protein as the brain benzodiazepine receptor with VDAC there may be even a mechanistic connection to the various symptoms of electromagnetic hypersensitive persons.

In the present state the influence of EMFs on biological systems is no longer a topic of theoretical interest but needs systematic experimental investigations to understand mechanisms and effects.

\section{Acknowledgements}

The authors thank Dr. Stefan Zbornik for valuable and competent discussion and comments on issues concerning telecommunication and related literature research.

\section{Conflicts of Interest}

The authors declare no conflicts of interest regarding the publication of this paper.

\section{References}

[1] Levitt, B.B. and Lai, H. (2010) Biological Effects from Exposure to Electromagnetic Radiation Emitted by Cell Tower Base Stations and Other Antenna Arrays. Environmental Reviews, 18, 365-395. https://doi.org/10.1139/A10-018

[2] Carpenter, D.O. (2013) Human Disease Resulting from Exposure to Electromagnetic Fields. Reviews on Environmental Health, 28, 159-172.

https://doi.org/10.1515/reveh-2013-0016

[3] Blank, M. and Goodman, R. (2009) Electromagnetic Fields Stress Living Cells. Pathophysiology, 16, 71-78. https://doi.org/10.1016/j.pathophys.2009.01.006

[4] Hardell, L. and Sage, C. (2008) Biological Effects from Electromagnetic Field Exposure and Public Exposure Standards. Biomed. Pharmacotherapy, 62, 104-109. https://doi.org/10.1016/j.biopha.2007.12.004

[5] Johansson, O. (2006) Electrohypersensitivity: State-of-the-Art of a Functional Impairment. Electromagnetic Biology and Medicine, 25, 245-258. https://doi.org/10.1080/15368370601044150

[6] McCarty, D.E., Carrubba, S., Chesson, A.L., Frilot, C., Gonzalez-Toledo, E. and Marino, A.A. (2011) Electromagnetic Hypersensitivity: Evidence for a Novel Neurological Syndrome. International Journal of Neuroscience, 121, 670-676. https://doi.org/10.3109/00207454.2011.608139

[7] Warnke, U. and Hensinger, P. (2013) Steigende "Burn-out"-Indiz durch technisch 
erzeugte magnetische und elektromagnetische Felder des Mabil-und Mommunikationsfunks. Kompetenzinitiative zum Schutz von Mensch, Umwelt und Demokratie e.V.

[8] La, V.S., Condorelli, R.A., Vicari, E., D’Agata, R. and Calogero, A.E. (2012) Effects of the Exposure to Mobile Phones on Male Reproduction: A Review of the Literature. Journal of Andrology, 33, 350-356. https://doi.org/10.2164/jandrol.111.014373

[9] West, J.G., Kapoor, N.S., Liao, S.-Y., Chen, J.W., Bailey, L. and Nagavney, R.A. (2013) Multifocal Breast Cancer in Young Women with Prolonged Contact between Their Breasts and Cellular Phones. Case Reports in Medicine, 2013, Article ID: 354682. https://doi.org/10.1155/2013/354682

[10] Falcioni, L., Bua, L., Tibaldi, E., Lauriola, M., De, A.L., Gnudi, F., Mandrioli, D., Manservigi, M., Manservisi, F., Manzoli, I., Menghetti, I., Montella, R., Panzacchi, S., Sgargi, D., Strollo, V., Vornoli, A. and Belpoggi, F. (2018) Report of Final Results Regarding Brain And heart Tumors in Sprague-Dawley Rats Exposed from Prenatal Life Until Natural Death to Mobile Phone Radiofrequency Field Representative of 1.8GHz GSM Base Station Environmental Emission. Environmental Research, 165, 496-503. https://doi.org/10.1016/j.envres.2018.01.037

[11] Sahin, D., Ozgur, E., Guler, G., Tomruk, A., Unlu, I., Sepici-Dincel, A. and Seyhan, N. (2016) The $2100 \mathrm{MHz}$ Radiofrequency Radiation of a 3G-Mobile Phone and the DNA Oxidative Damage in Brain. Journal of Chemical Neuroanatomy, 75, 94-98. https://doi.org/10.1016/j.jchemneu.2016.01.002

[12] Yakymenko, I. and Sidorik, E. (2010) Risks of Carcinogenesis from Electromagnetic Radiation of Mobile Telephony Devices. Experimental Oncology, 32, 54-60.

[13] D’Silva, M.H., Swer, R.T., Anbalagan, J. and Rajesh, B. (2017) Effect of Radiofrequency Radiation Emitted from 2G and 3G Cell Phone on Developing Liver of Chick Embryo-A Comparative Study. Journal of Clinical and Diagnostic Research, 11, AC05-AC09. https://doi.org/10.7860/JCDR/2017/26360.10275

[14] Siddiqi, N.S., Mathusami, J.C., Saad, S.M., Shafac, A. and Zaki, M. (2015) Effects of Mobile Phone $1800 \mathrm{~Hz}$ Electromagnetic Fields on the Development of Chick Embryo-A Pilot Study. International Conference on Chemical, Environmental and Biological Sciences, Dubai, 18-19 March 2015, 198-202.

[15] Hässig, M.R., Jud, F. and Spiess, B. (2012) Increased Occurrence of Nuclear Cataract in the Calf after Erection of a Mobile Phone Base Station. Schweizer Archiv für Tierheilkunde, 154, 82-86. https://doi.org/10.1024/0036-7281/a000300

[16] Dube, J., Rochette-Drouin, O., Levesque, P., Gauvin, R., Roberge, C.J., Auger, F.A., Goulet, D., Bourdages, M., Plante, M., Moulin, V.J. and Germain, L. (2012) Human Keratinocytes Respond to Direct Current Stimulation by Increasing Intracellular Calcium: Preferential Response of Poorly Differentiated Cells. Journal of Cellular Physiology, 227, 2660-2667. https://doi.org/10.1002/jcp.23008

[17] Nuccitelli, R. (2003) A Role for Endogenous Electric Fields in Wound Healing. Current Topics in Developmental Biology, 58, 1-26. https://doi.org/10.1016/S0070-2153(03)58001-2

[18] Zhang, X., Liu, X., Pan, L. and Lee, I. (2010) Magnetic Fields at Extremely Low-Frequency $(50 \mathrm{~Hz}, 0.8 \mathrm{mT})$ Can Induce the Uptake of Intracellular Calcium Levels in Osteoblasts. Biochemical and Biophysical Research Communications, 396, 662-666. https://doi.org/10.1016/j.bbrc.2010.04.154

[19] Zhou, J., Wang, J.Q., Ge, B.F., Ma, X.N., Ma, H.P., Xian, C.J. and Chen, K.M. (2014) Different Electromagnetic Field Waveforms Have Different Effects on Proliferation, Differentiation and Mineralization of Osteoblasts in Vitro. Bioelectromagnetics, 35, 30-38. https://doi.org/10.1002/bem.21794 
[20] Kirson, E.D., Gurvich, Z., Schneiderman, R., Dekel, E., Itzhaki, A., Wasserman, Y., Schatzberger, R. and Palti, Y. (2004) Disruption of Cancer Cell Replication by Alternating Electric Fields. Cancer Research, 64, 3288-3295. https://doi.org/10.1158/0008-5472.CAN-04-0083

[21] Blackman, C.F. (1992) Calcium Release from Neural Tissue: Experimental Results and Possible Mechanisms. In: Norden, B. and Ramel, C., Eds., Interaction Mechanisms of Low-Level Electromagnetic Fields in Living Systems, Oxford University Press, Oxford, 107-129.

[22] Pette, D. and Vrbova, G. (1992) Adaptation of Mammalian Skeletal Muscle Fibers to Chronic Electrical Stimulation. In: Reviews of Physiology, Biochemistry and Pharmacology, Vol. 120, Springer, Berlin, Heidelberg, 115-202. https://doi.org/10.1007/BFb0036123

[23] Klebl, B.M., Ayoub, A.T. and Pette, D. (1998) Protein Oxidation, Tyrosine Nitration, and Inactivation of Sarcoplasmic Reticulum $\mathrm{Ca}^{2+}$-ATPase in Low-Frequency Stimulated Rabbit Muscle. FEBS Letters, 422, 381-384. https://doi.org/10.1016/S0014-5793(98)00053-2

[24] Beckman, J.S. and Koppenol, W.H. (1996) Nitric Oxide, Superoxide, and Peroxynitrite: The Good, the Bad, and Ugly. American Journal of Physiology, 271, C1424-C1437. https://doi.org/10.1152/ajpcell.1996.271.5.C1424

[25] Carroll, S., Nicotera, P. and Pette, D. (1999) Calcium Transients in Single Fibers of Low-Frequency Stimulated Fast-Twitch Muscle of Rat. American Journal of Physiology, 277, C1122-C1129. https://doi.org/10.1152/ajpcell.1999.277.6.C1122

[26] Ermak, G. and Davies, K.J. (2002) Calcium and Oxidative Stress: From Cell Signaling to Cell Death. Molecular Immunology, 38, 713-721.

https://doi.org/10.1016/S0161-5890(01)00108-0

[27] Pall, M.L. (2013) Electromagnetic Fields Act via Activation of Voltage-Gated Calcium Channels to Produce Beneficial or Adverse Effects. Journal of Cellular and Molecular Medicine, 17, 958-965. https://doi.org/10.1111/jcmm.12088

[28] Berridge, M.J., Bootman, M.D. and Lipp, P. (1998) Calcium-A Life and Death Signal. Nature, 395, 645-648. https://doi.org/10.1038/27094

[29] Peng, T.I. and Jou, M.J. (2010) Oxidative Stress Caused by Mitochondrial Calcium Overload. Annals of the New York Academy of Sciences, 1201, 183-188. https://doi.org/10.1111/j.1749-6632.2010.05634.x

[30] Brookes, P.S., Yoon, Y., Robotham, J.L., Anders, M.W. and Sheu, S.S. (2004) Calcium, ATP, and ROS: A Mitochondrial Love-Hate Triangle. American Journal of Physiology: Cell Physiology, 287, C817-C833. https://doi.org/10.1152/ajpcell.00139.2004

[31] Pall, M.L. (2018) 5G: Great Risk for EU, U.S. and International Health! Compelling Evidence for Eight Distinct Types of Great Harm Caused by Eectromagnetic Field (EMF) Exposures and the Mechanism That Causes Them. 1-90. https://www.jrseco.com/wp-content/uploads/Martin_Pall_PhD_5G_Great_risk_for EE_US_and_International_Health-Compelling_Evidence.pdf

[32] Pilla, A.A. (2012) Electromagnetic Fields Instantaneously Modulate Nitric Oxide Signaling in Challenged Biological Systems. Biochemical and Biophysical Research Communications, 426, 330-333. https://doi.org/10.1016/j.bbrc.2012.08.078

[33] Lim, J.L., Wilhelmus, M.M., de Vries, H.E., Drukarch, B., Hoozemans, J.J. and van, H.J. (2014) Antioxidative Defense Mechanisms Controlled by Nrf2: State-of-the-Art and Clinical Perspectives in Neurodegenerative Diseases. Archives of Toxicology, 88, 1773-1786. 
[34] Friedman, J., Kraus, S., Hauptman, Y., Schiff, Y. and Seger, R. (2007) Mechanism of Short-Term ERK Activation by Electromagnetic Fields at Mobile Phone Frequencies. Biochemical Journal, 405, 559-568. https://doi.org/10.1042/BJ20061653

[35] Yumoto, H., Hirao, K., Tominaga, T., Bando, N., Takahashi, K. and Matsuo, T. (2015) Electromagnetic Wave Irradiation Promotes Osteoblastic Cell Proliferation and Up-Regulates Growth Factors via Activation of the ERK1/2 and p38 MAPK Pathways. Cellular Physiology and Biochemistry, 35, 601-615. https://doi.org/10.1159/000369722

[36] Wyatt, C.N., Weir, E.K. and Peers, C. (1994) Diphenylene Iodonium Blocks K ${ }^{+}$and $\mathrm{Ca}^{2+}$ Currents in Type I Cells Isolated from the Neonatal Rat Carotid Body. Neuroscience Letters, 172, 63-66. https://doi.org/10.1016/0304-3940(94)90663-7

[37] Morré, D.J. and Brightman, A.O. (1991) NADH Oxidase of Plasma Membranes. Journal of Bioenergetics and Biomembranes, 23, 469-489.

[38] Viappiani, S., Nicolescu, A.C., Holt, A., Sawicki, G., Crawford, B.D., Leon, H., van, M.T. and Schulz, R. (2009) Activation and Modulation of $72 \mathrm{kDa}$ Matrix Metalloproteinase- 2 by Peroxynitrite and Glutathione. Biochemical Pharmacology, 77, 826-834. https://doi.org/10.1016/j.bcp.2008.11.004

[39] Bruno, M., Brightman, A.O., Lawrence, J., Werderitsh, D., Morré, D.M. and Morré, D.J. (1992) Stimulation of NADH Oxidase Activity from Rat Liver Plasma Membranes by Growth Factors and Hormones Is Decreased or Absent with Hepatoma Plasma Membranes. Biochemical Journal, 284, 625-628. https://doi.org/10.1042/bj2840625

[40] Pou, S., Keaton, L., Surichamorn, W. and Rosen, G.M. (1999) Mechanism of Superoxide Generation by Neuronal Nitric-Oxide Synthase. Journal of Biological Chemistry, 274, 9573-9580. https://doi.org/10.1074/jbc.274.14.9573

[41] Sharpe, M.A. and Cooper, C.E. (1998) Reactions of Nitric Oxide with Mitochondrial Cytochrome C: A Novel Mechanism for the Formation of Nitroxyl Anion and Peroxynitrite. Biochemical Journal, 332, 9-19. https://doi.org/10.1042/bj3320009

[42] Ullrich, V. and Kissner, R. (2006) Redox Signaling: Bioinorganic Chemistry at Its Best. Journal of Inorganic Biochemistry, 100, 2079-2086.

https://doi.org/10.1016/j.jinorgbio.2006.09.019

[43] Ullrich, V. and Schildknecht, S. (2014) Sensing Hypoxia by Mitochondria: A Unifying Hypothesis Involving S-Nitrosation. Antioxidants \& Redox Signaling, 20, 325-338. https://doi.org/10.1089/ars.2012.4788

[44] Cheng, Q., Sedlic, F., Pravdic, D., Bosnjak, Z.J. and Kwok, W.M. (2011) Biphasic Effect of Nitric Oxide on the Cardiac Voltage-Dependent Anion Channel. FEBS Letters, 585, 328-334. https://doi.org/10.1016/j.febslet.2010.12.008

[45] De Pinto, V., Messina, A., Lane, D.J. and Lawen, A. (2010) Voltage-Dependent Anion-Selective Channel (VDAC) in the Plasma Membrane. FEBS Letters, 584, 1793-1799. https://doi.org/10.1016/j.febslet.2010.02.049

[46] Lawen, A., Ly, J.D., Lane, D.J., Zarschler, K., Messina, A. and De Pinto, V. (2005) Voltage-Dependent Anion-Selective Channel 1 (VDAC1)-A Mitochondrial Protein, Rediscovered as a Novel Enzyme in the Plasma Membrane. The International Journal of Biochemistry \& Cell Biology, 37, 277-282. https://doi.org/10.1016/j.biocel.2004.05.013

[47] Low, H., Crane, F.L. and Morré, D.J. (2012) Putting Together a Plasma Membrane NADH Oxidase: A Tale of Three Laboratories. The International Journal of Biochemistry \& Cell Biology, 44, 1834-1838.

https://doi.org/10.1016/j.biocel.2012.06.032 
[48] Ly, J.D. and Lawen, A. (2003) Transplasma Membrane Electron Transport: Enzymes Involved and Biological Function. Redox Report, 8, 3-21. https://doi.org/10.1179/135100003125001198

[49] Tang, X., Chueh, P.J., Jiang, Z., Layman, S., Martin, B., Kim, C., Morré, D.M. and Morré, D.J. (2010) Essential Role of Copper in the Activity and Regular Periodicity of a Recombinant, Tumor-Associated, Cell Surface, Growth-Related and Time-Keeping Hydroquinone (NADH) Oxidase with Protein Disulfide-Thiol Interchange Activity (ENOX2). Journal of Bioenergetics and Biomembranes, 42, 355-360. https://doi.org/10.1007/s10863-010-9305-8

[50] Shoshan-Barmatz, V. and Ginzel, D. (2003) The Voltage-Dependent Anion Channel. Cell Biochemistry and Biophysics, 39, 279-292.

https://doi.org/10.1385/CBB:39:3:279

[51] Yu, W.H., Wolfgang, W. and Forte, M. (1995) Subcellular Localization of Human Voltage-Dependent Anion Channel Isoforms. Journal of Biological Chemistry, 270, 13998-14006. https://doi.org/10.1074/jbc.270.23.13998

[52] Baker, M.A., Lane, D.J., Ly, J.D., De Pinto, V. and Lawen, A. (2004) VDAC1 Is a Transplasma Membrane NADH-Ferricyanide Reductase. Journal of Biological Chemistry, 279, 4811-4819. https://doi.org/10.1074/jbc.M311020200

[53] Buettner, R., Papoutsoglou, G., Scemes, E., Spray, D.C. and Dermietzel, R. (2000) Evidence for Secretory Pathway Localization of a Voltage-Dependent Anion Channel Isoform. Proceedings of the National Academy of Sciences of the United States of America, 97, 3201-3206. https://doi.org/10.1073/pnas.97.7.3201

[54] Báthori, G., Parolini, I., Tombola, F., Szabó, I., Messina, A., Oliva, M., De Pinto, V., Lisanti, M., Sargiacomo, M. and Zoratti, M. (1999) Porin Is Present in the Plasma Membrane Where It Is Concentrated in Caveolae and Caveolae-Related Domains. Journal of Biological Chemistry, 274, 29607-29612.

https://doi.org/10.1074/jbc.274.42.29607

[55] Bahamonde, M.I. and Valverde, M.A. (2003) Voltage-Dependent Anion Channel Localises to the Plasma Membrane and Peripheral but Not Perinuclear Mitochondria. Pflügers Archiv, 446, 309-313.

[56] Crane, F.L. and Low, H. (2012) The Oxidative Function of Diferric Transferrin. Biochemistry Research International, 2012, Article ID: 592806.

https://doi.org/10.1155/2012/592806

[57] Merker, M.P., Olson, L.E., Bongard, R.D., Patel, M.K., Linehan, J.H. and Dawson, C.A. (1998) Ascorbate-Mediated Transplasma Membrane Electron Transport in Pulmonary Arterial Endothelial Cells. American Journal of Physiology, 274, L685-L693. https://doi.org/10.1152/ajplung.1998.274.5.L685

[58] Messina, A., Reina, S., Guarino, F. and De Pinto, V. (2012) VDAC Isoforms in Mammals. Biochimica et Biophysica Acta, 1818, 1466-1476. https://doi.org/10.1016/j.bbamem.2011.10.005

[59] Aram, L., Geula, S., Arbel, N. and Shoshan-Barmatz, V. (2010) VDAC1 Cysteine Residues: Topology and Function in Channel Activity and Apoptosis. Biochemical Journal, 427, 445-454. https://doi.org/10.1042/BJ20091690

[60] Crane, F.L., Low, H., Navas, P. and Sun, I.L. (2013) Control of Cell Growth by Plasma Membrane NADH Oxidation. Pure and Applied Chemical Sciences, 1, 31-42. https://doi.org/10.12988/pacs.2013.3310

[61] Cheng, H.L., Lee, Y.H., Yuan, T.M., Chen, S.W. and Chueh, P.J. (2016) Update on a Tumor-Associated NADH Oxidase in Gastric Cancer Cell Growth. World Journal of Gastroenterology, 22, 2900-2905. https://doi.org/10.3748/wjg.v22.i10.2900 
[62] Hiller, S., Abramson, J., Mannella, C., Wagner, G. and Zeth, K. (2010) The 3D Structures of VDAC Represent a Native Conformation. Trends in Biochemical Sciences, 35, 514-521. https://doi.org/10.1016/j.tibs.2010.03.005

[63] Briones, R., Weichbrodt, C., Paltrinieri, L., Mey, I., Villinger, S., Giller, K., Lange, A., Zweckstetter, M., Griesinger, C., Becker, S., Steinem, C. and de Groot, B.L. (2016) Voltage Dependence of Conformational Dynamics and Subconducting States of VDAC-1. Biophysical Journal, 111, 1223-1234. https://doi.org/10.1016/j.bpj.2016.08.007

[64] Pastorino, J.G. and Hoek, J.B. (2008) Regulation of Hexokinase Binding to VDAC. Journal of Bioenergetics and Biomembranes, 40, 171-182. https://doi.org/10.1007/s10863-008-9148-8

[65] Sun, J. and Liao, J.K. (2002) Functional Interaction of Endothelial Nitric Oxide Synthase with a Voltage-Dependent Anion Channel. Proceedings of the National Academy of Sciences of the United States of America, 99, 13108-13113. https://doi.org/10.1073/pnas.202260999

[66] Tan, W. and Colombini, M. (2007) VDAC Closure Increases Calcium Ion Flux. Biochimica et Biophysica Acta, 1768, 2510-2515. https://doi.org/10.1016/j.bbamem.2007.06.002

[67] Villinger, S., Briones, R., Giller, K., Zachariae, U., Lange, A., de Groot, B.L., Griesinger, C., Becker, S. and Zweckstetter, M. (2010) Functional Dynamics in the Voltage-Dependent Anion Channel. Proceedings of the National Academy of Sciences of the United States of America, 107, 22546-22551.

https://doi.org/10.1073/pnas.1012310108

[68] Pavlov, E., Grigoriev, S.M., Dejean, L.M., Zweihorn, C.L., Mannella, C.A. and Kinnally, K.W. (2005) The Mitochondrial Channel VDAC Has a Cation-Selective Open State. Biochimica et Biophysica Acta, 1710, 96-102. https://doi.org/10.1016/j.bbabio.2005.09.006

[69] Noskov, S.Y., Rostovtseva, T.K., Chamberlin, A.C., Teijido, O., Jiang, W. and Bezrukov, S.M. (2016) Current State of Theoretical and Experimental Studies of the Voltage-Dependent Anion Channel (VDAC). Biochimica et Biophysica Acta, 1858, 1778-1790. https://doi.org/10.1016/j.bbamem.2016.02.026

[70] Colombini, M. (2016) The VDAC Channel: Molecular Basis for Selectivity. Biochimica et Biophysica Acta, 1863, 2498-2502. https://doi.org/10.1016/j.bbamcr.2016.01.019

[71] Bahamonde, M.I., Fernandez-Fernandez, J.M., Guix, F.X., Vazquez, E. and Valverde, M.A. (2003) Plasma Membrane Voltage-Dependent Anion Channel Mediates Antiestrogen-Activated Maxi $\mathrm{Cl}^{-}$Currents in C1300 Neuroblastoma Cells. Journal of Biological Chemistry, 278, 33284-33289. https://doi.org/10.1074/jbc.M302814200

[72] Elinder, F., Akanda, N., Tofighi, R., Shimizu, S., Tsujimoto, Y., Orrenius, S. and Ceccatelli, S. (2005) Opening of Plasma Membrane Voltage-Dependent Anion Channels (VDAC) Precedes Caspase Activation in Neuronal Apoptosis Induced by Toxic Stimuli. Cell Death and Differentiation, 12, 1134-1140. https://doi.org/10.1038/sj.cdd.4401646

[73] Kozuch, J., Weichbrodt, C., Millo, D., Giller, K., Becker, S., Hildebrandt, P. and Steinem, C. (2014) Voltage-Dependent Structural Changes of the Membrane-Bound Anion Channel hVDAC1 Probed by SEIRA and Electrochemical Impedance Spectroscopy. Physical Chemistry Chemical Physics, 16, 9546-9555.

https://doi.org/10.1039/C4CP00167B

[74] Song, J., Midson, C., Blachly-Dyson, E., Forte, M. and Colombini, M. (1998) The 
Sensor Regions of VDAC Are Translocated from within the Membrane to the Surface during the Gating Processes. Biophysical Journal, 74, 2926-2944. https://doi.org/10.1016/S0006-3495(98)78000-2

[75] Báthori, G., Szabó, I., Schmehl, I., Tombola, F., Messina, A., De Pinto, V. and Zoratti, M. (1998) Novel Aspects of the Electrophysiology of Mitochondrial Porin. Biochemical and Biophysical Research Communications, 243, 258-263. https://doi.org/10.1006/bbrc.1997.7926

[76] Benz, R. (1994) Permeation of Hydrophilic Solutes through Mitochondrial Outer Membranes: Review on Mitochondrial Porins. Biochimica et Biophysica Acta, 1197, 167-196. https://doi.org/10.1016/0304-4157(94)90004-3

[77] Tsujimoto, Y. and Shimizu, S. (2002) The Voltage-Dependent Anion Channel: An Essential Player in Apoptosis. Biochimie, 84, 187-193.

https://doi.org/10.1016/S0300-9084(02)01370-6

[78] Ben-Hail, D. and Shoshan-Barmatz, V. (2016) VDAC1-Interacting Anion Transport Inhibitors Inhibit VDAC1 Oligomerization and Apoptosis. Biochimica et Biophysica Acta, 1863, 1612-1623. https://doi.org/10.1016/j.bbamcr.2016.04.002

[79] Rostovtseva, T.K. and Bezrukov, S.M. (2008) VDAC Regulation: Role of Cytosolic Proteins and Mitochondrial Lipids. Journal of Bioenergetics and Biomembranes, 40, 163-170. https://doi.org/10.1007/s10863-008-9145-y

[80] Xu, Z., Zhang, D., He, X., Huang, Y. and Shao, H. (2016) Transport of Calcium Ions into Mitochondria. Current Genomics, 17, 215-219.

https://doi.org/10.2174/1389202917666160202215748

[81] Montero, M., Alonso, M.T., Carnicero, E., Cuchillo-Ibanez, I., Albillos, A., Garcia, A.G., Garcia-Sancho, J. and Alvarez, J. (2000) Chromaffin-Cell Stimulation Triggers fast Millimolar Mitochondrial $\mathrm{Ca}^{2+}$ Transients That Modulate Secretion. Nature Cell Biology, 2, 57-61. https://doi.org/10.1038/35000001

[82] Gincel, D., Silberberg, S.D. and Shoshan-Barmatz, V. (2000) Modulation of the Voltage-Dependent Anion Channel (VDAC) by Glutamate. Journal of Bioenergetics and Biomembranes, 32, 571-583.

[83] Gincel, D., Vardi, N. and Shoshan-Barmatz, V. (2002) Retinal Voltage-Dependent Anion Channel: Characterization and Cellular Localization. Investigative Ophthalmology \& Visual Science, 43, 2097-2104.

[84] Thinnes, F.P. (2013) New Findings Concerning Vertebrate Porin II-On the Relevance of Glycine Motifs of Type-1 VDAC. Molecular Genetics and Metabolism, 108, 212-224. https://doi.org/10.1016/j.ymgme.2013.01.008

[85] Denora, N. and Natile, G. (2017) An Updated View of Translocator Protein (TSPO). International Journal of Molecular Sciences, 18, 2640.

https://doi.org/10.3390/ijms18122640

[86] Rupprecht, R., Papadopoulos, V., Rammes, G., Baghai, T. C., Fan, J., Akula, N., Groyer, G., Adams, D. and Schumacher, M. (2010) Translocator Protein (18 kDa) (TSPO) as a Therapeutic Target for Neurological and Psychiatric Disorders. Nature Reviews Drug Discovery, 9, 971-988. https://doi.org/10.1038/nrd3295

[87] Barichello, T., Simoes, L.R., Collodel, A., Giridharan, V.V., Dal-Pizzol, F., Macedo, D. and Quevedo, J. (2017) The Translocator Protein (18 kDa) and Its Role in Neuropsychiatric Disorders. Neuroscience \& Biobehavioral Reviews, 83, 183-199. https://doi.org/10.1016/j.neubiorev.2017.10.010

[88] Braestrup, C. and Squires, R.F. (1977) Specific Benzodiazepine Receptors in Rat Brain Characterized by High-Affinity (3H)Diazepam Binding. Proceedings of the National Academy of Sciences of the United States of America, 74, 3805-3809. 
https://doi.org/10.1073/pnas.74.9.3805

[89] Wang, H., Zhai, K., Xue, Y., Yang, J., Yang, Q., Fu, Y., Hu, Y., Liu, F., Wang, W., Cui, L., Chen, H., Zhang, J. and He, W. (2016) Global Deletion of TSPO Does Not Affect the Viability and Gene Expression Profile. PLOS ONE, 11, e0167307. https://doi.org/10.1371/journal.pone.0167307

[90] Liu, G.J., Middleton, R.J., Hatty, C.R., Kam, W.W., Chan, R., Pham, T., Harrison-Brown, M., Dodson, E., Veale, K. and Banati, R.B. (2014) The 18 kDa Translocator Protein, Microglia and Neuroinflammation. Brain Pathology, 24, 631-653. https://doi.org/10.1111/bpa.12196

[91] Czajkowski, C., Gibbs, T.T. and Farb, D.H. (1989) Transmembrane Topology of the Gamma-Aminobutyric AcidA/Benzodiazepine Receptor: Subcellular Distribution and Allosteric Coupling Determined in Situ. Molecular Pharmacology, 35, 75-84.

[92] Liedvogel, M. and Mouritsen, H. (2010) Cryptochromes-A Potential Magnetoreceptor: What Do We Know and What Do We Want to Know? Journal of the Royal Society Interface, 7, S147-S162. https://doi.org/10.1098/rsif.2009.0411.focus

[93] Byrdin, M., Eker, A.P., Vos, M.H. and Brettel, K. (2003) Dissection of the Triple Tryptophan Electron Transfer Chain in Escherichia coli DNA Photolyase: Trp382 Is the Primary Donor in Photoactivation. Proceedings of the National Academy of Sciences of the United States of America, 100, 8676-8681.

https://doi.org/10.1073/pnas.1531645100

[94] Henbest, K.B., Maeda, K., Hore, P.J., Joshi, M., Bacher, A., Bittl, R., Weber, S., Timmel, C.R. and Schleicher, E. (2008) Magnetic-Field Effect on the Photoactivation Reaction of Escherichia coli DNA Photolyase. Proceedings of the National Academy of Sciences of the United States of America, 105, 14395-14399. https://doi.org/10.1073/pnas.0803620105

[95] Maeda, K., Robinson, A.J., Henbest, K.B., Hogben, H.J., Biskup, T., Ahmad, M., Schleicher, E., Weber, S., Timmel, C.R. and Hore, P.J. (2012) Magnetically Sensitive Light-Induced Reactions in Cryptochrome Are Consistent with Its Proposed Role as a Magnetoreceptor. Proceedings of the National Academy of Sciences of the United States of America, 109, 4774-4779. https://doi.org/10.1073/pnas.1118959109

[96] Cashmore, A.R., Jarillo, J.A., Wu, Y.J. and Liu, D. (1999) Cryptochromes: Blue Light Receptors for Plants and Animals. Science, 284, 760-765.

[97] Kattnig, D.R. (2017) Radical-Pair-Based Magnetoreception Amplified by Radical Scavenging: Resilience to Spin Relaxation. The Journal of Physical Chemistry B, 121, 10215-10227. https://doi.org/10.1021/acs.jpcb.7b07672

[98] Rodgers, C.T. and Hore, P.J. (2009) Chemical Magnetoreception in Birds: The Radical Pair Mechanism. Proceedings of the National Academy of Sciences of the United States of America, 106, 353-360. https://doi.org/10.1073/pnas.0711968106

[99] Bialas, C., Jarocha, L.E., Henbest, K.B., Zollitsch, T.M., Kodali, G., Timmel, C.R., Mackenzie, S.R., Dutton, P.L., Moser, C.C. and Hore, P.J. (2016) Engineering an Artificial Flavoprotein Magnetosensor. Journal of the American Chemical Society, 138, 16584-16587. https://doi.org/10.1021/jacs.6b09682

[100] Grebing, C., Crane, F.L., Low, H. and Hall, K. (1984) A Transmembranous NADH-Dehydrogenase in Human Erythrocyte Membranes. Journal of Bioenergetics and Biomembranes, 16, 517-533.

[101] Kennett, E.C. and Kuchel, P.W. (2003) Redox Reactions and Electron Transfer across the Red Cell Membrane. IUBMB Life, 55, 375-385.

https://doi.org/10.1080/15216540310001592843

[102] Matteucci, E. and Giampietro, O. (2007) Electron Pathways through Erythrocyte 
Plasma Membrane in Human Physiology and Pathology: Potential Redox Biomarker? Biomarker Insights, 2, 321-329. https://doi.org/10.1177/117727190700200026

[103] Sridharan, M., Bowles, E.A., Richards, J.P., Krantic, M., Davis, K.L., Dietrich, K.A., Stephenson, A.H., Ellsworth, M.L. and Sprague, R.S. (2012) Prostacyclin Receptor-Mediated ATP Release from Erythrocytes Requires the Voltage-Dependent Anion Channel. American Journal of Physiology-Heart and Circulatory Physiology, 302, H553-H559. https://doi.org/10.1152/ajpheart.00998.2011

[104] Kaestner, L., Wang, X., Hertz, L. and Bernhardt, I. (2018) Voltage-Activated Ion Channels in Non-Excitable Cells-A Viewpoint Regarding Their Physiological Justification. Frontiers in Physiology, 9, 450. https://doi.org/10.3389/fphys.2018.00450

[105] Kaestner, L., Christophersen, P., Bernhardt, I. and Bennekou, P. (2000) The Non-Selective Voltage-Activated Cation Channel in the Human Red Blood Cell Membrane: Reconciliation between Two Conflicting Reports and Further Characterisation. Bioelectrochemistry, 52, 117-125.

https://doi.org/10.1016/S0302-4598(00)00110-0

[106] Marginedas-Freixa, I., Alvarez, C.L., Moras, M., Leal Denis, M.F., Hattab, C., Halle, F., Bihel, F., Mouro-Chanteloup, I., Lefevre, S.D., Le Van, K.C., Schwarzbaum, P.J. and Ostuni, M.A. (2018) Human Erythrocytes Release ATP by a Novel Pathway Involving VDAC Oligomerization Independent of Pannexin-1. Scientific Reports, 8, Article No. 11384. https://doi.org/10.1038/s41598-018-29885-7

[107] Baskurt, O., Neu, B. and Meiselman, H.J. (2019) Red Blood Cell Aggregation. CRC Press, Boca Raton, FL.

[108] Wagner, C., Steffen, P. and Svetina, S. (2013) Aggregation of Red Blood Cells: From Rouleaux to Clot Formation. Comptes Rendus Physique, 14, 459-469.

https://doi.org/10.1016/j.crhy.2013.04.004

[109] Danielczok, J.G., Terriac, E., Hertz, L., Petkova-Kirova, P., Lautenschlager, F., Laschke, M.W. and Kaestner, L. (2017) Red Blood Cell Passage of Small Capillaries Is Associated with Transient $\mathrm{Ca}^{2+}$-Mediated Adaptations. Frontiers in Physiology, 8 , 979. https://doi.org/10.3389/fphys.2017.00979

[110] Sebastián, J.L., San Martín, S.M., Sancho, M., Miranda, J.M. and Álvarez, G. (2005) Erythrocyte Rouleau Formation under Polarized Electromagnetic Fields. Physical Review E, 72, Article ID: 031913. https://doi.org/10.1103/PhysRevE.72.031913

[111] Kaestner, L., Bogdanova, A. and Egee, S. (2020) Calcium Channels and Calcium-Regulated Channels in Human Red Blood Cells. In: Islam, M., Eds., Advances in Experimental Medicine and Biology, Vol. 1131, Springer, Cham, 625-648. https://doi.org/10.1007/978-3-030-12457-1_25

[112] Lang, K.S., Duranton, C., Poehlmann, H., Myssina, S., Bauer, C., Lang, F., Wieder, T. and Huber, S.M. (2003) Cation Channels Trigger Apoptotic Death of Erythrocytes. Cell Death and Differentiation, 10, 249-256. https://doi.org/10.1038/sj.cdd.4401144

[113] Cortese-Krott, M.M. and Kelm, M. (2014) Endothelial Nitric Oxide Synthase in Red Blood Cells: Key to a New Erythrocrine Function? Redox Biology, 2, 251-258. https://doi.org/10.1016/j.redox.2013.12.027

[114] Raccuglia, D., Huang, S., Ender, A., Heim, M.M., Laber, D., Suarez-Grimalt, R., Liotta, A., Sigrist, S.J., Geiger, J.R.P. and Owald, D. (2019) Network-Specific Synchronization of Electrical Slow-Wave Oscillations Regulates Sleep Drive in Drosophila. Current Biology, 29, 3611-3621. https://doi.org/10.1016/j.cub.2019.08.070

[115] Igarashi, J., Isomura, Y., Arai, K., Harukuni, R. and Fukai, T. (2013) A $\theta-\gamma$ Oscillation Code for Neuronal Coordination during Motor Behavior. Journal of Neuros- 
cience, 33, 18515-18530. https://doi.org/10.1523/JNEUROSCI.2126-13.2013

[116] Weintraub, K. (2011) The Prevalence Puzzle: Autism Counts. Nature, 479, 22-24. https://doi.org/10.1038/479022a

[117] Mariea, T.J. and Carlo, G. L. (2007) Wireless Radiation in the Etiology and Treatment of Autism: Clinical Observations and Mechanisms. Journal of the Australasian College of Nutritional \& Environmental Medicine, 26, 3-7.

[118] Gonzalez-Gronow, M., Cuchacovich, M., Francos, R., Cuchacovich, S., Fernandez, M.P., Blanco, A., Bowers, E.V., Kaczowka, S. and Pizzo, S.V. (2010) Antibodies against the Voltage-Dependent Anion Channel (VDAC) and Its Protective Ligand Hexokinase-I in Children with Autism. Journal of Neuroimmunology, 227, 153-161. https://doi.org//10.1016/j.jneuroim.2010.06.001

[119] Kern, J.K. (2002) The Possible Role of the Cerebellum in Autism/PDD: Disruption of a Multisensory Feedback Loop. Medical Hypotheses, 59, 255-260. https://doi.org/10.1016/S0306-9877(02)00212-8

[120] Langen, M., Durston, S., Staal, W.G., Palmen, S.J. and van, E.H. (2007) Caudate Nucleus Is Enlarged in High-Functioning Medication-Naive Subjects with Autism. Biological Psychiatry, 62, 262-266. https://doi.org/10.1016/j.biopsych.2006.09.040

[121] Sogut, S., Zoroglu, S.S., Ozyurt, H., Yilmaz, H.R., Ozugurlu, F., Sivasli, E., Yetkin, O., Yanik, M., Tutkun, H., Savas, H.A., Tarakcioglu, M. and Akyol, O. (2003) Changes in Nitric Oxide Levels and Antioxidant Enzyme Activities May Have a Role in the Pathophysiological Mechanisms Involved in Autism. Clinica Chimica Acta, 331, 111-117. https://doi.org/10.1016/S0009-8981(03)00119-0

[122] Crane, F.L., Low, H., Sun, I., Navas, P. and Gvozdjakova, A. (2014) Plasma Membrane Coenzyme Q: Evidence for a Role in Autism. Biologics, 8, 199-205. https://doi.org/10.2147/BTT.S53375

[123] Mutter, J., Naumann, J., Schneider, R., Walach, H. and Haley, B. (2005) Mercury and Autism: Accelerating Evidence? Neuro Enocrinology Letters, 26, 439-446.

[124] Hashimoto, T., Tayama, M., Murakawa, K., Yoshimoto, T., Miyazaki, M., Harada, M. and Kuroda, Y. (1995) Development of the Brainstem and Cerebellum in Autistic Patients. Journal of Autism and Developmental Disorders, 25, 1-18.

[125] Kubova, H., Bendova, Z., Moravcova, S., Pacesova, D., Rocha, L.L. and Mares, P. (2018) Neonatal Clonazepam Administration Induces Long-Lasting Changes in Glutamate Receptors. Frontiers in Molecular Neuroscience, 11, 382. https://doi.org/10.3389/fnmol.2018.00382 